IVE MAÍRA DE CARVALHO DANTAS

\title{
PERFIL LIPÍDICO NA LESHMANIOSE VISCERAL EM HAMSTER E EXPRESSÃO DE mRNA DE GENES RELACIONADOS AO METABOLISMO LIPROPROTÉICO
}

Dissertação apresentada ao Instituto de Medicina Tropical da Universidade de São Paulo para obtenção do título de Mestre em Ciências

Área de concentração: Doenças Tropicais e Saúde Internacional

Orientadora: Profa. Dra. Hiro Goto 
Ficha catalográfica

Preparada pela Biblioteca do Instituto de Medicina Tropical de São Paulo da Universidade de São Paulo (c) Reprodução autorizada pelo autor

Dantas, Ive Maíra de Carvalho

Perfil lipídico na leshmaniose visceral em hamster e expressão de mRNA de genes relacionados ao metabolismo liproprotéico / Ive Maíra de Carvalho Dantas. - São Paulo, 2013.

Dissertação (Mestrado) - Instituto de Medicina Tropical de São Paulo da Universidade de São Paulo para obtenção do título de Mestre em Ciências.

Área de concentração: Doenças Tropicais e Saúde Internacional Orientador: Hiro Goto 
A Deus, que nos possibilita a vida, nos fortalece e motiva durante nossa jornada.

Ao meu marido, Vinícius, por ser meu melhor amigo, companheiro e por sempre me incentivar em todos os meus objetivos.

Aos meus pais, José e Selma, e as minhas irmãs, Carla e Milena, obrigada pelo apoio e dedicação e principalmente pelo exemplo que representam em minha vida. 


\section{AGRADECIMENTOS}

Agradeço a todos que de alguma forma contribuíram para este projeto, principalmente a profa. Dra. Hiro Goto pela experiência e oritentação e a minha coorientadora Ms. Flaviane Pinho pelo auxílio no desenvolvimento deste projeto.

Gostaria de salientar minha gratidão especialmente à aluna Amanda Torres por participar deste trabalho durante toda jornada e pela amizade tão especial que compartilhamos neste período. Aos alunos, ex-alunos e funcionários do laboratório meus sinceros agradecimentos, pois sem vocês este estudo não seria possível (Aline Martins, Amanda Castanheira, Amanda Texeira, Ms. André Fonseca, Ariane Leal, Ms. Beatriz Celeste, Camila Sato, Dra. Célia Vendrame, Ms. Christiane Ozaki, Ms. Débora Picanço, Dra. Edna Souza, Dr. Eduardo Sanchez, Filipe Cunha, Guilherme Barssotti, Dr. Igor Silva, Lilian Farias, Dra. Luíza Reis, Ms. Sara Boni, Simone Petri), principalmente na participação de experimentos com animais! Aos professores, funcionários e alunos do $4^{\circ}$ andar da medicina tropical, como Ariane Sanchez, Elisabete Ourique, Ms. Edite Kanashiro, Dra. Guita Elephant, Mussya Rocha, Ms. Thaynan Martins, William Roldan pelo carinho e simpatia.

A Dra. Sandra Castro pela alegria e simpatia que tanto nos contagiava no laboratório e pela participação no projeto em vários dos experimentos sendo sempre tão dedicada! Ao prof. Dr. Ângelo Lindoso pelo carinho, amor e respeito com o qual trata a todos no seu ambiente de trabalho, sendo sempre tão gentil e humilde!

A profa. Dra. Patrícia Cazita e Dra. Valéria Nunes pela simpatia, conhecimento e sugestões importantes, além de possibilitarem a realização das dosagens lipídicas e atividades do plasma no laboratório de lípides da Faculdade de Medicina/USP.

Meu sincero reconhecimento ao apoio financeiro da Fundação de Amparo à Pesquisa do Estado de São Paulo (FAPESP) pela bolsa de mestrado fornecida para o desenvolvimento deste projeto (processo 2011/03768-1). Ao CNPq, FINEP e LIM-38 pelo financiamento e ao CNPq também pela bolsa de mestrado.

Muito obrigada ao Instituto de Medicina Tropical de São Paulo e ao Programa de Pós-graduação em Doenças Tropicais e Saúde Internacional. 


\section{RESUMO}

Dantas, IMC. Perfil lipídico na leshmaniose visceral em hamster e expressão de mRNA de genes relacionados ao metabolismo liproprotéico (dissertação). São Paulo: Instituto de Medicina Tropical de São Paulo da Universidade São Paulo; 2013.

$\mathrm{Na}$ fase ativa da leishmaniose visceral (LV) ocorrem alterações no metabolismo de lipoproteínas com redução dos níveis de HDL e aumento de triglicérides. A partir desses dados, focamos neste projeto essas alterações na progressão da infecção e apontamos alguns elementos como seus possíveis desencadeantes. Como essas alterações poderiam resultar de redução de atividade e expressão da lipoproteína lipase (LPL), do receptor alfa do proliferador ativado de peroxissoma (PPAR $\alpha$ ) e da proteína transferidora de ésteres de colesteril (CETP), a sua expressão foi avaliada durante a progressão da LV em hamster. Em hamsteres infectados com $2 \times 10^{7}$ amastigotas de $L$. (L.) infantum observamos aumento de triglicérides nos hamsteres com 55 dias $($ mediana $=294,0 \mathrm{mg} / \mathrm{dL})$ e 90 dias $(303,0 \mathrm{mg} / \mathrm{dL})$ de infecção comparados aos controles de 55 dias $(119,0 \mathrm{mg} / \mathrm{dL})$ e de 90 dias $(117,0 \mathrm{mg} / \mathrm{dL})(\mathrm{p} \leq$ 0,05). Os níveis de colesterol total e de HDL não apresentaram diferença significante entre controles e infectados com 30, 55 e 90 dias de infecção. A expressão de mRNA de PPAR $\alpha$ no fígado com 55 e 90 dias de infecção apresentou tendência de redução nos infectados. Já de CETP no fígado dos hamsteres com 55 dias de infecção, a expressão relativa $(\triangle \mathrm{CT})$ estava reduzida nos infectados $(0,08)$ comparados aos controles $(1,69)(\mathrm{p} \leq 0,05)$ e de LPL no coração dos hamsteres com 90 dias de infecção também estava reduzida $(1,43)$ com relação aos controles $(2,61)(p \leq 0,05)$. Há dados na literatura sugerindo a importância de lipídios para o desenvolvimento de amastigotas no hospedeiro vertebrado e é possível que as alterações dos níveis de lipoproteínas contribuam na progressão da infecção. Assim, avaliamos neste estudo o efeito da droga hipolipemiante ciprofibrato no controle do parasitismo na LV em hamster, sabendo-se que ciprofibratos atuam aumentando a expressão de PPAR $\alpha$ e a produção e atividade de LPL. O tratamento com ciprofibrato nos hamsteres com 55 dias de infecção gerou redução de triglicérides $(123,0 \mathrm{mg} / \mathrm{dL})$ em relação aos 
infectados não tratados $(294,0 \mathrm{~g} / \mathrm{dL})(\mathrm{p} \leq 0,05)$, além dos níveis de triglicérides nos animais infectados não tratados terem aumentado quando comparados aos controles não tratados $(119,0 \mathrm{mg} / \mathrm{dL})(\mathrm{p} \leq 0,05)$. Houve também, redução de triglicérides nos animais não infectados tratados com ciprofibrato $(89,0 \mathrm{mg} / \mathrm{dL})$ comparando-se aos infectados não tratados $(\mathrm{p} \leq 0,05)$. Os níveis de colesterol nos hamsteres não infectados tratados com ciprofibrato reduziram $(53,5 \mathrm{mg} / \mathrm{dL})$ em comparação aos infectados não tratados $(93,0 \mathrm{mg} / \mathrm{dL})(\mathrm{p} \leq 0,05)$. Já naqueles que foram infectados e tratados com ciprofibrato, constatamos redução de colesterol $(53,5 \mathrm{mg} / \mathrm{dL})$ quando comparados aos infectados não tratados $(\mathrm{p} \leq 0,05)$. Os níveis de HDL não aumentaram com ciprofibrato e foram similares entre os hamsteres infectados não tratados e os controles não tratados. A carga parasitária no baço e no fígado não foi reduzida com ciprofibrato. Na leishmaniose visceral em hamster ocorrem alterações do metabolismo lipídico com aumento de triglicérides e redução da expressão da mRNA de LPL e CETP. O tratamento com ciprofibrato foi eficaz no controle das alterações de níveis de lipoproteínas.

Descritores: Leishmaniose visceral. Lipídeos - metabolismo. Hamsters. Peroxissomos. Lipoproteínas. RNA mensageiro. 


\begin{abstract}
Dantas, IMC. Lipid profile in visceral leishmaniasis in hamster and expression of mRNA of genes related to lipoprotein metabolism (dissertação). São Paulo: Instituto de Medicina Tropical de São Paulo da Universidade São Paulo; 2013.

In the active phase of visceral leishmaniasis (VL) changes occur in lipoprotein metabolism with reduction in HDL and increase in triglyceride (TG) levels. From these data, in this project we focused these changes during the progression of the infection and we approached some elements as their underlying factors. Since these changes may result from the reduction of the activity and the expression of the lipoprotein lipase (LPL), of the peroxisome proliferator-activated receptor alpha (PPAR $\alpha$ ) and of the cholesteryl ester transfer protein (CETP), their expression were evaluated during VL progression in hamster. In $2 \times 10^{7} L$. (L.) infantum amastigote-infected hamsters we observed an increase in the triglycerides in hamsters with 55 days (median = $294.0 \mathrm{mg} / \mathrm{dL})$ and 90 days $(303.0 \mathrm{mg} / \mathrm{dL})$ of infection compared with controls of 55 days $(119.0 \mathrm{mg} / \mathrm{dL})$ and of 90 days $(117.0 \mathrm{mg} / \mathrm{dL})(\mathrm{p} \leq 0.05)$. The total cholesterol and the HDL levels did not present significant differences between control and infected groups at 30,55 and 90 days of infection. The expression of mRNA of the PPAR in the liver with 55 and 90 days of infection tended to be reduced in infected animals. However the relative expression $(\Delta \mathrm{CT})$ of CETP in the liver of hamsters with 55 days of infection was signicantly reduced in infected (0.08) compared with control animals $(1.69)(\mathrm{p} \leq 0.05)$. The relative expression $(\Delta \mathrm{CT})$ of LPL in the heart of hamsters with 90 days of infection was also reduced (1.43) in relation to controls (2.61) $(\mathrm{p} \leq 0.05)$. There are data in the literature suggesting the importance of lipids for the development of amastigotes in vertebrate host and it is possible that the changes in the lipoprotein levels contribute for the infection progression. Therefore, we evaluated in this study the effect of the lipid-lowering drug ciprofibrate in the control of parasitism in VL in the hamster, knowing that ciprofibrate acts increasing the expression of the PPAR $\alpha$ and of the LPL production and activity. The treatment with ciprofibrate in infected hamsters at 55 days lead to the reduction of triglyceride
\end{abstract}


level $(123.0 \mathrm{mg} / \mathrm{dL})$ in relation to non-treated infected animals $(294.0 \mathrm{~g} / \mathrm{dL})(\mathrm{p} \leq$ $0.05)$. Further the triglyceride levels in the non-treated infected animals were increased when compared with untreated controls $(119.0 \mathrm{mg} / \mathrm{dL})(\mathrm{p} \leq 0.05)$. There was also reduction of triglyceride in ciprofibrate treated-non infected animals (89.0 $\mathrm{mg} / \mathrm{dL})$ compared with non-treated infected animals $(\mathrm{p} \leq 0.05)$. The cholesterol levels were reduced in the ciprofibrate-treated non-infected hamsters $(53.5 \mathrm{mg} / \mathrm{dL})$ in comparison to the non-treated infected ones $(93.0 \mathrm{mg} / \mathrm{dL})(\mathrm{p} \leq 0.05)$. In the ciprofibrate-treated infected ones we found a reduction of cholesterol level (53.5 $\mathrm{mg} / \mathrm{dL})$ when compared with non treated infected animals $(\mathrm{p} \leq 0.05)$. The HDL levels did not increase with ciprofibrate and they were similar between the non-treated infected hamsters and non-treated controls. The parasite load in the spleen and liver were not reduced with ciprofibrate. In the visceral leishmaniasis in hamster changes occur in the lipid metabolism with increase in the triglyceride level and the reduction of expression of mRNA of LPL and CETP. The treatment with ciprofibrate was effective in the control of changes in the lipoprotein levels.

Descriptors: Visceral leishmaniasis. Lipids - metabolism. Hamsters. Peroxisomes. Lipoproteins. Messenger RNA. 


\section{LISTA DE ABREVIATURAS, SÍMBOLOS E SIGLAS}

\begin{tabular}{|c|c|}
\hline LV & Leishmaniose Visceral \\
\hline L. (L.) infantum & Leishmania (Leishmania) infantum \\
\hline WHO & World Health Organization \\
\hline USA & United States of America \\
\hline DNA & Deoxyribonucleic acid \\
\hline cDNA & Complementary deoxyribonucleic acid \\
\hline RNA & Ribonucleic acid \\
\hline mRNA & Messenger ribonucleic acid \\
\hline qPCR & Real Time Polymerase Chain Reaction \\
\hline TG & Triglicérides \\
\hline HDL & High Density Lipoprotein \\
\hline VLDL & Very Low Density Lipoprotein \\
\hline IDL & Intermediate Density Lipoprotein \\
\hline LDL & Low Density Lipoprotein \\
\hline Apo & Apolipoproteína \\
\hline $\operatorname{PPAR} \alpha$ & Receptor alfa do proliferador ativado de peroxissoma \\
\hline LPL & Lipoproteína lipase \\
\hline CETP & Proteína transferidora de ésteres de colesteril \\
\hline LCAT & Lecitina colesterol acil transferase \\
\hline SRBI & Scavenger receptor class B type I \\
\hline LXR & Liver $X$ receptor \\
\hline SREBP-1 & Sterol regulatory element binding protein \\
\hline IL & Interleucina \\
\hline IMTSP & Instituto de Medicina Tropical de São Paulo \\
\hline
\end{tabular}




\section{LISTA DE TABELAS}

\section{Página}

Tabela 1 - Sequência de iniciadores (primers) com número de acesso, temperatura de anelamento e tamanho do produto amplificado. 


\section{LISTA DE FIGURAS}

Página

Figura 1- Concentração de triglicérides (mediana e percentis de $25 \%$ e $75 \%$ ) no plasma de hamsteres controles e infectados aos 30, 55 e 90 dias de infecção.

Figura 2- Concentração de colesterol total (mediana e percentis de $25 \%$ e $75 \%$ ) no plasma de hamsteres controles e infectados aos 30, 55 e 90 dias de infecção.

Figura 3- Concentração de HDL (mediana e percentis de $25 \%$ e $75 \%$ ) no plasma de hamsteres controles e infectados aos 30, 55 e 90 dias de infecção.

Figura 4- Curva de melting dos produtos amplificados por qPCR de PPAR $\alpha$, CETP, LPL e $\beta$-actina.

Figura 5- Expressão relativa $(\Delta \mathrm{CT})$ de mRNA de PPAR $\alpha$ calculada em relação a expressão de mRNA de $\beta$-actina ( $\Delta \mathrm{CT})$ no fígado de hamsteres com 55 (A) e 90 dias (B) de infecção (mediana e percentis de $25 \%$ e $75 \%$ ).

Figura 6- Expressão relativa $(\triangle \mathrm{CT})$ de mRNA de CETP foi calculada em relação a expressão de mRNA de $\beta$-actina $(\Delta \mathrm{CT})$ no fígado de hamsteres com 55 dias de infecção (mediana e percentis de $25 \%$ e $75 \%)$.

Figura 7- Expressão relativa $(\triangle \mathrm{CT})$ de mRNA de LPL foi calculada em relação a expressão de mRNA de $\beta$-actina $(\Delta \mathrm{CT})$ no coração de hamsteres com 90 dias de infecção (mediana e percentis de $25 \%$ e $75 \%$ ).

Figura 8- Concentração de triglicérides (mediana e percentis de $25 \%$ e $75 \%$ ) no plasma de hamsteres infectados e não infectados, com e sem tratamento com sorbitol ou ciprofibrato $(19,3 \mathrm{mg} / \mathrm{Kg})$ com 55 dias pós-infecção.

Figura 9- Concentração de colesterol total (com mediana e percentis de $25 \%$ e $75 \%$ ) no plasma de hamsteres infectados e não infectados, com e sem tratamento com sorbitol ou ciprofibrato $(19,3 \mathrm{mg} / \mathrm{Kg})$ com 55 dias pós-infecção.

Figura 10- Concentração de HDL (com mediana e percentis de $25 \%$ e $75 \%$ ) no plasma de hamsteres infectados e não infectados, com e sem tratamento com sorbitol ou ciprofibrato $(19,3 \mathrm{mg} / \mathrm{Kg})$ com 55 dias pós-infecção.

Figura 11- Carga parasitária (com mediana e percentis de $25 \%$ e $75 \%$ ) por microscopia óptica no baço e fígado de hamsteres infectados sem tratamento, tratados com sorbitol e tratados com ciprofibrato $(19,3$ $\mathrm{mg} / \mathrm{Kg}$ ) com 55 dias pós-infecção. 


\section{SUMÁRIO}

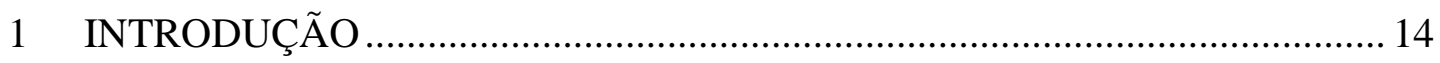

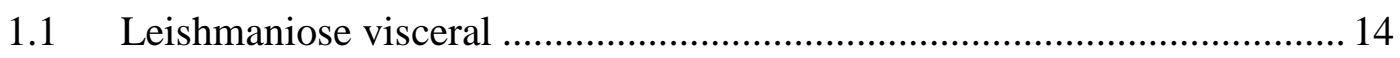

1.2 Alterações nos níveis de lipoproteínas na leishmaniose visceral ................. 15

1.3 Lipoproteínas durante a infecção por L. (L.) infantum ............................. 17

1.4 Fatores relacionados a alterações lipídicas na LV .................................. 18

1.5 Leishmaniose visceral experimental em hamster ................................. 20

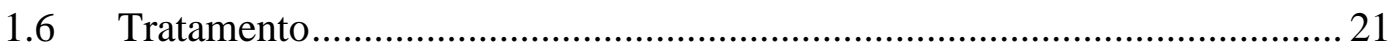

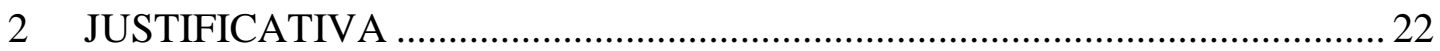

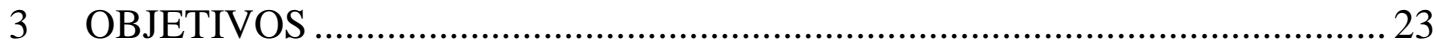

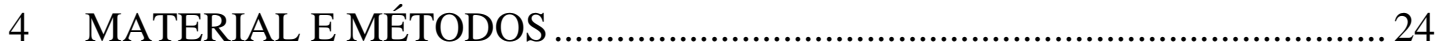

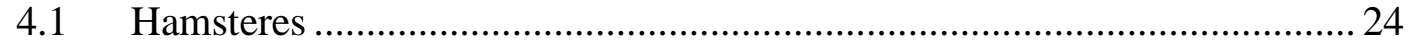

4.2 Parasito e preparação do inóculo.................................................................. 24

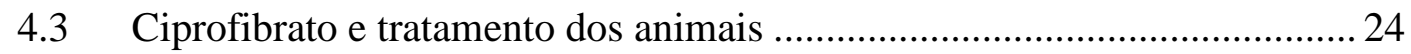

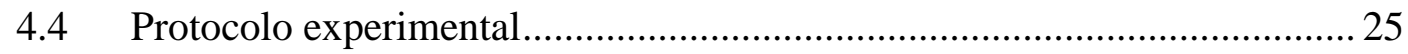

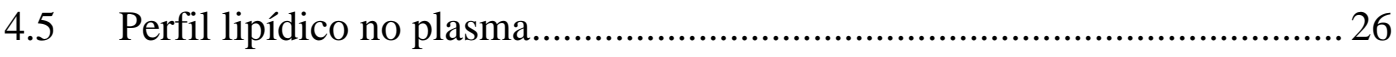

4.6 Avaliação da carga parasitária............................................................... 26

4.6.1 Quantificação por microscopia óptica ................................................. 26

4.7 Avaliação da expressão de mRNA de PPAR $\alpha$, CETP e LPL por qPCR na

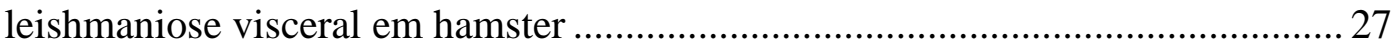

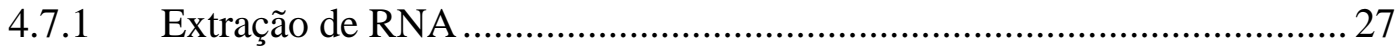

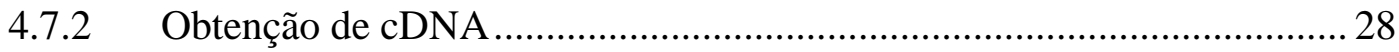

4.7.3 PCR em tempo real para expressão gênica.............................................. 28

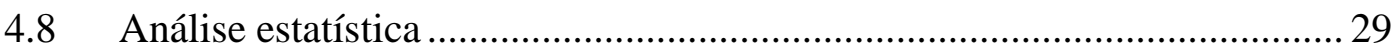

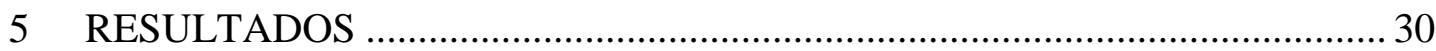


5.1 Perfil lipídico durante a evolução de leishmaniose visceral em hamster .... 30

5.2 Avaliação da expressão de mRNA de PPAR $\alpha$, CETP e LPL por qPCR na leishmaniose visceral em hamster

5.3 Efeito do tratamento com ciprofibrato nos níveis de lipoproteínas e na carga

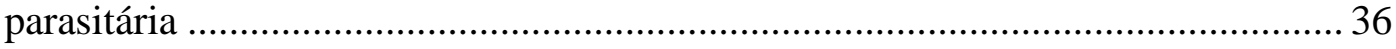

5.3.1 Avaliação da carga parasitária .................................................................. 39

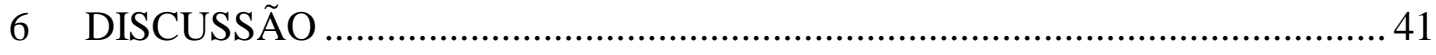

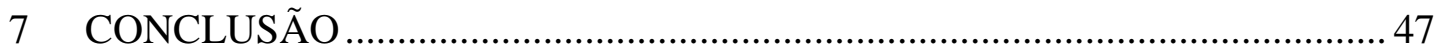

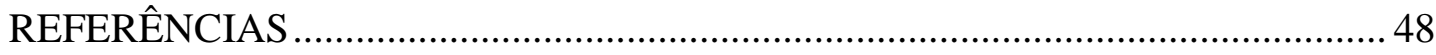

ANEXO A - Comitê de Ética do IMTSP/USP ........................................................ 56 


\section{INTRODUÇÃO}

\subsection{Leishmaniose visceral}

Leishmanioses são doenças causadas por protozoários da ordem Kinetoplastida, família Trypanosomatidae, gênero Leishmania e são transmitidas por dípteros de gêneros Phlebotomus e Lutzomyia, no Velho Mundo e Novo Mundo, respectivamente, conhecidos como flebotomíneos (Myler e Fasel, 2008). Dependendo da espécie do parasito e da resposta do hospedeiro, podem determinar leishmaniose visceral (LV) ou várias formas da doença tegumentar (Bañuls et al, 2007).

A classificação das espécies de leishmânias inicialmente foi baseada nas características clínicas, geográficas e biológicas, mas a partir de 1970, critérios imunológicos, genéticos e bioquímicos também foram incluídos para a definição taxonômica. As principais espécies de Leishmania são classificadas em dois subgêneros: Leishmania e Viannia. O subgênero Viannia compreende quatro complexos bem definidos: Leishmania (V.) brasiliensis, Leishmania (V.) guyanensis, Leishmania (V.) naiffi, Leishmania (V.) lainsoni. O subgênero Leishmania compreende onze complexos, sendo cinco destes patogêncios ao homem: $L$. (L.) mexicana, L. (L.) amazonensis, L. (L.) major, L. (L.) donovani e L. (L.) infantum (Bañuls et al, 2007).

A leishmaniose visceral (LV) é considerada a mais grave e está presente em 66 países com 90\% dos casos ocorrendo na Índia, Sudão, Bangladesh, Nepal e Brasil. A estimativa é de 500.000 novos casos em todo mundo, e no Brasil de aproximadamente 3.000 a cada ano onde a espécie Leishmania (Leishmania) infantum é responsável pela LV (WHO, 2010).

$\mathrm{Na}$ LV os parasitos se reproduzem em mamíferos suscetíveis nas células do sistema fagocítico mononuclear de órgãos linfóides como baço, fígado e medula óssea, sob a forma amastigota, com aspecto arredondado e sem flagelo externo. No 
inseto vetor, reproduzem-se no tubo digestivo, sob a forma promastigota que é alongada e com presença de flagelo externo (Brasil, 2009).

Em relação as manifestações clínicas, os hospedeiros podem ser assintomáticos, oligossintomáticos ou sintomáticos. Casos assintomáticos se caracterizam por sorologia positiva ou teste de Montenegro (teste de hipersensibilidade tardia a antígenos de Leishmania) positivo. Os oligossintomáticos apresentam febre baixa ou ausente, hepatomegalia, esplenomegalia discreta ou ausente, adinamia. Os sintomáticos apresentam a manifestação plena da doença com febre, hepatoesplenomegalia, pancitopenia, hipergamaglobulinemia e grande comprometimento do estado geral (Myler e Fasel, 2008). Na fase ativa da LV plenamente manifesta, observam-se também alterações nos níveis de lipoproteínas séricas cujas repercussões na patogenia são pouco conhecidas (Liberopoulos et al, 2002; Soares et al, 2010).

A resistência ou a suscetibilidade à infecção por $L$. (L.) infantum estão relacionados à ativação de diferentes populações e subpopulações de linfócitos $\mathrm{T}$, embora na LV não seja clara a dicotomia da resposta, em Th1 ligada à resistência e Th2 à suscetibilidade (Goto e Lindoso, 2004; Goto e Prianti, 2009). Ao lado da resposta imune adaptativa, outros fatores também contribuem para o estabelecimento e progressão da infecção (Ghosh et al, 2013; Khovidhunkit et al, 2000; Soares et al, 2010). Neste estudo, focaremos as lipoproteínas como fatores contribuintes para a evolução da infecção, apontando possíveis fatores desencadeantes de alterações lipoprotéicas e o efeito do tratamento das alterações lipídicas no controle do parasitismo.

\subsection{Alterações nos níveis de lipoproteínas na leishmaniose visceral}

O colesterol é um componente essencial da estrutura da membrana das células e fica incorporado nas partículas de lipoproteínas plasmáticas. Apresenta-se na forma de colesterol livre, combinado com longa cadeia de ácidos graxos (triglicérides - TG) ou como éster de colesterol. As lipoproteínas plasmáticas são responsáveis por transportar o colesterol livre na circulação (Bansal et al, 2005). 
De acordo com sua densidade as lipoproteínas são divididas em cinco classes: quilomícrons, Very Low Density Lipoprotein (VLDL), Intermediate Density Lipoprotein (IDL), Low Density Lipoprotein (LDL) e High Density Lipoprotein (HDL) (Gotto et al, 1986). As lipoproteínas são partículas constituídas por TG, colesterol esterificado, fosfolipídios, colesterol livre, vitaminas lipossolúveis, além de um conjunto de proteínas, as apolipoproteínas (apo), que mantém a estabilidade e solubilidade das diferentes partículas em meio aquoso (Hoeg e Brewer, 1986).

Os quilomícrons e as VLDL apresentam predominantemente TG em sua constituição, enquanto as HDL possuem maior proporção de fosfolipídios e proteínas (Hoeg e Brewer, 1986). As VLDL, responsáveis pelo transporte de TG de origem hepática, são partículas grandes e têm como principal constituinte a apo B-100, enquanto que nos quilomícrons é a apo B-48 (Genest, 2003; Yao e Mcleod, 1994). Essas partículas secretadas pelo fígado são metabolizadas pela mesma via dos quilomícrons, interagindo com a lipoproteína lipase (LPL), enzima responsável pela hidrólise dos TG em monoglicerídio e ácidos graxos, transformando-se progressivamente em remanescente de VLDL ou IDL. A IDL pode ser convertida pela ação da lipase hepática em LDL (Goldberg, 1996).

As HDL são sintetizadas no fígado e intestino ou a partir das lipoproteínas ricas em TG pela ação da LPL periférica, apresentam maior relevância na sua constituição a apo A-I e a apo A-II e são responsáveis pela remoção do excesso de colesterol das células e seu transporte reverso para o fígado e subsequente depósito para excreção na bile. A LDL é a principal transportadora de colesterol na circulação (Forte et al, 1993; Genest, 2003). As partículas de HDL nascentes sofrem esterificação do colesterol pela ação da enzima lecitina colesterol acil transferase (LCAT), e na sequência a proteína transferidora de ésteres de colesteril (CETP) atua transferindo este conteúdo esterificado das HDL para as lipoproteínas ricas em apo B e também captam triglicérides destas lipoproteínas para HDL que retorna ao fígado pelo scavenger receptor class B type I (SR-BI) (Quintão e Cazita, 2010).

Os dados na literatura em LV são de relatos de casos ou estudos com poucos pacientes. Em casos clínicos reportados de LV, foi observada hipocolesterolemia, hipertrigliceridemia e redução de HDL e LDL (Agouridis et al, 2012; Lal et al, 2007; Liberopoulos et al, 2002). Assim como em 32 indivíduos com 
LV ocorreu redução de HDL e colesterol total com tendência de aumento de triglicérides (Ottoni, 2010). Noutros 26 pacientes com LV comparados a 26 controles foram observados níveis circulantes elevados de triglicérides e VLDL, e marcada redução dos níveis de colesterol total, LDL, HDL e apo A, e uma modesta redução da apo B (Soares et al, 2010). Em dois casos em crianças com LV as concentrações plasmáticas de HDL antes do tratamento foram significativamente mais baixas, enquanto os níveis de triglicerídeos no plasma estavam aumentados (Seçmeer et al, 2006). No estudo desenvolvido por Bekaert et al (1989), em 17 crianças com LV ocorreu hipertrigliceridemia e redução de HDL.

Já num estudo em 16 cães de áreas endêmicas, infectados naturalmente com Leishmania infantum e 10 cães saudáveis observou-se um aumento significante dos níveis de colesterol, triglicérides e LDL nos cães infectados, porém, houve significante redução dos níveis de HDL (Nieto et al, 1992), entretanto, segundo Durgut et al (2012), em 10 cães com LV comparados com 10 cães controles houve aumento apenas do colesterol e redução de triglicérides e HDL. Em hamsteres infectados pela $L$. donovani observou-se alta concentração de lipídeos no soro, como triglicérides após 60 dias de infecção (Vasconcelos et al, 1996).

Em estudo prévio do grupo da professora Hiro Goto com um número significante de amostras de pacientes com LV de Teresina, Piauí, observaram-se níveis altos de TG e baixos de HDL (a ser publicado). A partir desses dados, focamos essas alterações na evolução da infecção e apontamos alguns elementos como desencadeantes dessas alterações.

\subsection{Lipoproteínas durante a infecção por L. (L.) infantum}

As alterações dos níveis de lipoproteínas podem ser consequência do processo infeccioso, mas há dados que sugerem que lípides podem favorecer a progressão da infecção. Na membrana plasmática há lipid rafts que são microdomínios ricos em colesterol ou esfingolipídios com funções de transporte, transdução de sinal, endocitose e porta de entrada a patógenos (Chakraborty et al, 2005). Pucadyil et al (2004) afirmaram que a depleção do colesterol resultou em redução significante da extensão da infecção por Leishmania donovani. Em relação a 
esse resultado, o tratamento utilizado com metil- $\beta$-ciclodextrina, que remove o colesterol da membrana plasmática de macrófagos, pode ter impedido a entrada de promastigotas nas células, porém, sem o colesterol a célula também pode ter-se tornado inviável.

Há outros dados, baseados em análise proteômica, indicando também que, as amastigotas, teriam maior necessidade de proteína e lípides na sua geração de energia quando comparadas a promastigotas (Rosenzweig et al, 2008).

Essas partículas lipoprotéicas são, por outro lado, capazes de modular a resposta imune celular, pois inibem a proliferação de linfócitos in vitro. Os macrófagos possuem receptores de lipoproteínas naturais ou modificados e, portanto, são possíveis alvos para as atividades imunomodulatórias destas partículas. Estudos recentes reportam que a depleção de colesterol da membrana das células do hospedeiro prejudica a penetração de patógenos intracelulares como a Leishmania (Soares et al, 2010; Vasconcelos et al, 1996).

\subsection{Fatores relacionados a alterações lipídicas na $\mathrm{LV}$}

No metabolismo lipoprotéico, a LPL desempenha um papel essencial e sua expressão e ativação é estimulada pelo receptor alfa do proliferador ativado de peroxissoma $(\operatorname{PPAR} \alpha)$. Este gera o aumento da produção e a ativação da LPL e redução da apo CIII, mecanismos estes que estimulam a diminuição da VLDL e quilomícrons por lipólise de TG com a beta oxidação dos ácidos graxos no fígado. Neste processo elevam os níveis de HDL por gerar uma produção maior da Apo AI e, pelo incremento da lipólise de TG, aumenta também a oferta dos componentes de superfície da HDL (Fiegenbaum e Hutz, 2006; Kersten et al, 2000; Schoonjans et al, 1996). A CETP é ativada pelo liver $X$ receptor (LXR) na presença de dieta rica em colesterol ou pelo sterol regulatory element binding protein-1 (SREBP-1) e também apresenta importância no metabolismo lipoprotéico por estar associada ao transporte reverso do colesterol (Luo e Tall, 2000; Kim e Spielgeman, 1996).

O PPAR $\alpha$ é altamente expresso em tecidos envolvidos na oxidação de ácidos graxos como fígado, intestino delgado, coração, rim, músculo esquelético e 
pâncreas (Braissant et al, 1996; Viswakarma et al, 2010). O sinal de expressão da LPL não foi detectado em fígado de rato adulto utilizando hibridização in situ (Semenkovich et al, 1989; Yacoub et al, 1990). Em outro estudo densenvolvido também com hibridização in situ em hamster, foi detectada alta expressão de mRNA da CETP nos tecidos adiposo, cardíaco e muscular esquelético, com nível similar de expressão de mRNA da LPL nestes tecidos, mas expressão baixa no fígado (Jiang et al, 1991).

A ativação do PPARa gera liberação da LPL que promove oxidação de ácidos graxos no peroxissomo a acetil-CoA e inibição da biossíntese de ácidos graxos intracelulares por reduzir a expressão da enzima acil-CoA carboxilase não convertendo acetil-CoA a malonil CoA, e também inibe a sintase de ácidos graxos que converte o substrato anterior a acil-CoA (Kersten et al, 2000; Schoonjans et al, 1996).

Em relação a infecções, no estudo conduzido por de Gottardi et al (2006), observou-se que na hepatite $\mathrm{C}$ crônica ocorre redução de cerca de $85 \%$ da expressão de mRNA de PPAR $\alpha$ no fígado, particularmente naqueles com esteatose e que essa supressão de PPAR $\alpha$ esteja relacionada à aceleração da replicação do vírus.

Variações na expressão dos genes da LPL e sua regulação podem influenciar a sua função e contribuir para doenças como dislipidemia, diabetes do tipo II, evolução da coronariopatia cardíaca, hipertensão arterial e doença de Alzheimer. Várias observações clínicas têm sugerido que os pacientes com deficiência de LPL sofrem de hipertrigliceridemia grave com diminuição da atividade e expressão da LPL (Xie et al, 2010).

$\mathrm{Na}$ literatura sugere-se que CETP apresenta papel pró-aterogênico por contribuir na redistribuição de colesterol esterificado da HDL para as lipoproteínas ricas em apo B e também é associado a aterosclerose já que o aumento de atividade da CETP estimula redução dos níveis de HDL. Entretanto, possui papel antiaterogênico também, por redistribuir triglicérides destas lipoproteínas para o fígado. Além disso, dados mostram CETP relacionado a proteção durante processos inflamatórios e infecciosos (Cazita et al, 2008; Tall et al, 1984).

Em parasitoses, obervou-se que a maturação e embrionamento dos ovos de Schistosoma japonicum em cultura dependem de nutrientes onde a presença de 
HDL e ésteres de colesteril é necessária para formação do miracídio. Estes dados demonstram a importância da CETP no desenvolvimento da infecção parasitária (Okumura-Noji et al, 2013).

Com relação a pacientes com $L V$, supomos que possíveis alterações na expressão de PPAR $\alpha$, da LPL e da CETP possam ocorrer, determinando alterações nos níveis de lipoproteínas e com possível influência subsequentemente na progressão da doença.

\subsection{Leishmaniose visceral experimental em hamster}

Diferentes modelos animais são utilizados para estudos com LV, como os camundongos isogênicos, cão e hamster. Dentre estes modelos experimentais, no presente estudo, optamos pelo hamster.

Nos cães a doença por LV é similar à humana, com anemia, aumento dos linfonodos e febre, além da infecção poder se desenvolver assintomática, diferindo da LV humana pela presença de alterações de pele nesta espécie animal (Abranches et al, 1991; Pinelli et al, 1995). No entanto, a evolução da infecção é muito prolongada e variável tornando-se um grande obstáculo em estabelecê-lo como modelo experimental.

Camundongos isogênicos também são utilizados como modelos para se estudar a LV. No entanto, mesmo nas linhagens BALB/c e C57BL/6 que são consideradas suscetíveis, há progressão da infecção somente nas primeiras semanas ocorrendo controle posterior da replicação do parasito com formação de granuloma (Murray et al, 1987; Barbosa Júnior et al, 1987), não reproduzindo a doença progressiva humana.

No estudo de Stauber (1958), o hamster sírio dourado (Mesocricetus auratus) foi considerado como extremamente suscetível à infecção por Leishmania. Ele é um excelente modelo para se estudar a LV por desenvolver, assim como no homem, caquexia progressiva, hepatoesplenomegalia, pancitopenia, hipergamaglobulinemia evoluindo para a morte (Hommel et al, 1995; Melby et al, 2001). 


\subsection{Tratamento}

Os fibratos ou derivados do ácido fíbrico são fármacos hipolipemiantes que reduzem os níveis de triglicérides e colesterol e aumentam HDL. Seu mecanismo de ação está relacionado à sua ligação a fatores de transcrição PPARs (receptores do proliferador ativado de peroxissoma) e modulação de genes envolvidos no metabolismo lipídico. A LPL, responsável pela hidrólise de triglicerídeos, tem sua expressão aumentada com a ativação do fator de transcrição PPAR $\alpha$. Além disso, os fibratos diminuem a produção de apo $\mathrm{B}$, a expressão de apo C-III, VLDLs e conversão de VLDL em LDL. (Fiegenbaum e Hutz, 2006; Goldenberg et al, 2008). Apresentam ainda ações antioxidantes, diminuindo a oxidação das LDLs, ações antitrombóticas e anti-inflamatórias. Estas ações são decorrentes também da ativação dos PPAR, que inibe a expressão de IL-1 e IL-6, da cicloxigenase-2, da proteína-C reativa, das moléculas de adesão, do fator tecidual, do fibrinogênio, do inibidor do ativador do plasminogênio e genes das prostaglandinas (Goldenberg et al, 2008; Staels et al, 1998).

No tratamento, os fibratos podem reduzir, em média, TG em 35\%, podendo chegar aos $60 \%$ nos pacientes hipertrigliceridêmicos graves, reduzir LDL de 10 a $31 \%$, diminuir a proporção de LDL pequena e densa e elevar a HDL em até $22 \%$ (Staels et al, 1998; Martinez e Santos, 2004).

Os ciprofibratos também aumentam HDL com concomitante aumento de apo A-I e A-II. Segundo Pirela e colaboradores (2005), o ciprofibrato aumentou 25\% de HDL enquanto que foi de apenas 9,6\% no grupo que só realizou dieta.

Num estudo prévio preliminar no grupo da professora Hiro Goto (a ser publicado), hamsteres com LV apresentaram níveis elevados de TG e os animais com LV tratados com ciprofibrato, apresentaram redução nos níveis de TG e tendência à diminuição da carga parasitária. 


\section{JUSTIFICATIVA}

Estudos demonstram que alterações no metabolismo lipoprotéico ocorrem durante a infecção na fase ativa da LV com redução dos níveis de HDL e aumento de TG. A partir desses dados, analisamos essas alterações na progressão da infecção em hamsteres com LV e apontamos alguns elementos como possíveis desencadeantes dessas alterações, quais sejam a redução de atividade e expressão da LPL, do PPAR $\alpha$ e da CETP. A expressão da LPL, do PPAR $\alpha$ e da CETP foi avaliada durante a progressão da LV em hamster.

Há dados na literatura sugerindo a importância de lipídios para o desenvolvimento de amastigotas no hospedeiro vertebrado e é possível que as alterações dos níveis de lipoproteínas contribuam na progressão da infecção. Os fibratos, ou derivados do ácido fíbrico, se mostram eficazes no tratamento de pacientes com hipertrigliceridemia combinada com níveis baixos de HDL, tendo fortes efeitos nas partículas de LDL. Sabe-se também que ciprofibratos atuam aumentando a expressão do fator de transcrição PPAR $\alpha$ e a produção e atividade da LPL, elementos que serão avaliados como desencadeantes das alterações de lipoproteínas na LV ativa. Desta forma, propomos o estudo do efeito da droga hipolipemiante ciprofibrato no controle das alterações de lipoproteínas e do parasitismo na LV em hamster. 


\section{OBJETIVOS}

\section{Objetivo geral}

- Em hamster infectado por Leishmania (Leishmania) infantum, caracterizar as alterações do perfil lipídico, avaliar a expressão de LPL, PPAR $\alpha$ e CETP como fatores desencadeantes das alterações lipídicas e o efeito do tratamento com ciprofibrato no controle das alterações dos níveis de lipoproteínas e da carga parasitária.

\section{Objetivos específicos}

- Avaliar o hamster como modelo experimental para o metabolismo lipoprotéico na leishmaniose visceral

- Determinar as alterações de triglicérides, colesterol total e HDL em hamsteres infectados por L. (L.) infantum e os controles.

- Avaliar a expressão de mRNA de LPL, PPAR $\alpha$ e CETP entre os hamsteres infectados por L. (L.) infantum e os controles.

- Avaliar as alterações do perfil lipídico e da carga parasitária com tratamento com ciprofibrato nos hamsteres infectados e não infectados. 


\section{MATERIAL E MÉTODOS}

\subsection{Hamsteres}

Hamsteres (Mesocricetus auratus) não isogênicos, machos, 45 a 60 dias de idade, fornecidos pelo Centro de Bioterismo da Faculdade de Medicina da Universidade de São Paulo foram mantidos no Biotério de Experimentação do Instituto de Medicina Tropical (IMT) da Universidade de São Paulo em ambiente com ventilação natural, com ração (Purina, PR, Brasil) e água à vontade.

\subsection{Parasito e preparação do inóculo}

L. (L.) infantum, cepa MHOM/BR/1972/46, foi mantida em hamsteres no Biotério de Experimentação do IMT com inoculações intraperitoneais periódicas de homogeneizado de baço de animais infectados. Para a obtenção de amastigotas para os experimentos, baços de animais infectados foram macerados com meio RPMI 1640 (GIBCO, EUA), filtrados em gaze estéril e passados quatro vezes por agulhas 19 G, 21 G e 24 G para rompimento de células esplênicas e liberação de amastigotas. A suspensão foi centrifugada a $250 \mathrm{~g}$ a $4^{\circ} \mathrm{C}$ por 10 minutos, o sobrenadante submetido à nova centrifugação nas mesmas condições, seguido de centrifugação por 30 minutos a $1200 \mathrm{~g} \mathrm{a} 4^{\circ} \mathrm{C}$. O sedimento contendo amastigotas foi submetido a contagem pela Câmara de Newbauer e ressuspenso em meio RPMI 1640 com a concentração de parasitos acertada para $2 \times 10^{7} / \mathrm{mL}$.

\subsection{Ciprofibrato e tratamento dos animais}

O ciprofibrato foi preparado de forma estéril em farmácia nas concentrações de 7,6 mg/mL, $15 \mathrm{mg} / \mathrm{mL}, 50 \mathrm{mg} / \mathrm{mL}$ e $100 \mathrm{mg} / \mathrm{mL}$, em sorbitol simples a $2 \%$ qsp para $1 \mathrm{~mL}$. Também foi preparado separadamente sorbitol a $2 \%$ 
qsp para $1 \mathrm{~mL}$ sem ciprofibrato (placebo). As soluções foram acondicionadas em frascos âmbar de vidro contendo $10 \mathrm{~mL}$ cada.

O ciprofibrato e o sorbitol foram administrados diariamente por via oral com auxílio de agulha de gavagem num volume de $0,5 \mathrm{~mL}$ contendo doses variáveis, conforme o experimento, durante 10 dias e em alguns experimentos num volume de $1 \mathrm{~mL}$ durante 15 dias.

\subsection{Protocolo experimental}

Hamsteres foram infectados por via intraperitoneal com $2 \times 10^{7}$ amastigotas purificadas de $L$. (L.) infantum em um $\mathrm{mL}$ e foram eutanasiados nos períodos de 30, 55, 75 e 90 dias pós-infecção. Em paralelo, mantivemos grupos controle em que foi administrado por via intraperitoneal meio RPMI 1640. Alguns hamsteres foram submetidos à avaliação evolutiva das alterações do perfil lipídico apenas com controles e infectados, e outros ao tratamento com ciprofibrato. A coleta de sangue periférico foi realizada por punção retro-orbitária com os hamsteres anestesiados utilizando-se isoflurano (Baxter Healthcare, USA) por via inalatória (com concentração alveolar mínima de 1,5\%), para este procedimento a máscara química e capela química foram utilizadas, e posteriormente, os animais foram eutanasiados utilizando-se a câmera de $\mathrm{CO}_{2}$. O sangue periférico foi processado para obtenção do plasma que foi armazenado a $-80^{\circ} \mathrm{C}$ para as dosagens das frações lipídicas, o baço e o fígado coletados dos animais eutanasiados foram pesados e utilizados para preparação dos imprints em lâmina para avaliação da carga parasitária e fragmentos de $25 \mathrm{mg}$ de fígado e de coração foram armazenados a $-80^{\circ} \mathrm{C}$ para posteriores análises para determinar a expressão de mRNA de PPAR $\alpha$, LPL e CETP.

Realizamos experimentos com as doses de ciprofibrato de $19,3 \mathrm{mg} / \mathrm{kg}$ de peso apenas nos animais eutanasiados aos 55 dias e 75 dias pós-infecção, e nas doses de $76 \mathrm{mg} / \mathrm{kg}, 250 \mathrm{mg} / \mathrm{kg}$ e $500 \mathrm{mg} / \mathrm{kg}$ de peso dos hamsteres após 75 dias de infecção. Para o tratamento naqueles com 55 dias pós-infecção dividimos os hamsteres em seis diferentes grupos contendo 37 animais ao total, estes grupos são, controle sem tratamento, controle tratado com sorbitol, controle tratado com ciprofibrato, infectado sem tratamento, infectado tratado com sorbitol, e infectado 
tratado com ciprofibrato. Cada grupo apresentava 6 animais, exceto o grupo de infectado tratado com ciprofibrato que possuía 7 hamsteres. Devido a baixa carga parasitária detectada, 1 hamster infectado sem tratamento e 3 hamsteres dos grupos de infectado tratado com sorbitol e infectado tratado com ciprofibato foram retirados dos dados. O tratamento foi realizado por 10 dias após 45 dias de infecção ou por 15 dias após 60 dias de infecção. Os hamsteres foram eutanasiados com 55 ou 75 dias de infecção, respectivamente.

Nos animais com 30 dias pós-infecção foram utilizados 5 controles e 4 infectados, e naqueles com 90 dias pós-infecção foram utilizados 5 controles e 6 infectados. Para os experimentos de padronização do tratamento com ciprofibrato foram utilizados 3 animais infectados por cada grupo com as doses de $76 \mathrm{mg} / \mathrm{kg}, 250$ $\mathrm{mg} / \mathrm{kg}$ e $500 \mathrm{mg} / \mathrm{kg}$ de peso.

\subsection{Perfil lipídico no plasma}

O plasma que foi separado do sangue periférico e armazenado a $-80^{\circ} \mathrm{C}$ foi descongelado e utilizado $150 \mu \mathrm{L}$ para dosagem de colesterol total por método enzimático-colorimétrico e triglicérides por método colorimétrico, e $250 \mu \mathrm{L}$ para obtenção de apenas HDL-colesterol do plasma adicionando-se $25 \mu \mathrm{L}$ de precipitantes de apo B (sulfato de dextrana e cloreto de magnésio) e centrifugação a 956 g por 30 minutos a $4{ }^{\circ} \mathrm{C}$. O sobranadante foi coletado e utilizado para dosagem de HDLcolesterol pelo método enzimático-colorimétrico. Utilizamos kits da Labtest diagnósticos SA (Minas Gerais, Brasil) e o aparelho automatizado Cobas Mira Plus, Roche, (Basiléia, Suíça) do Laboratório de Lípides da Faculdade de Medicina da USP (LIM-10).

\subsection{Avaliação da carga parasitária}

\subsubsection{Quantificação por microscopia óptica}

O fígado e o baço foram pesados e preparados os imprints em lâminas com coloração por Panótico (Newprov, Paraná, Brasil) para contagem de formas amastigotas de leishmânia e células mononucleares em microscópio de luz Zeiss 
(Axiolab) na objetiva de aumento de $100 \mathrm{x}$, segundo o método descrito por Stauber (1958), contando-se até 1000 células ou leishmânias de cada amostra. Para o cálculo da carga parasitária, a média de leishmânias/células foi multiplicado pelo peso do órgão (mg) e o fator $2 \times 10^{4}$.

\subsection{Avaliação da expressão de mRNA de PPARa, CETP e LPL por qPCR na leishmaniose visceral em hamster}

Fragmentos de fígado e de coração de hamsteres com 55 e 90 dias de infecção, de controles e infectados (sem tratamento) foram utilizados para determinar a expressão de mRNA de PPAR $\alpha$, LPL e CETP. A expressão de mRNA de LPL foi determinada com amostra de coração (90 dias de infecção). Estes fragmentos foram acondicionados em microtubos (Eppendorf, Hamburgo, Alemanha) contendo $400 \mu \mathrm{L}$ do reagente TRIZOL (Invitrogen, USA) e armazenados em $-80{ }^{\circ} \mathrm{C}$.

\subsubsection{Extração de RNA}

Fragmentos de $25 \mathrm{mg}$ de fígado e coração foram descongelados e macerados e em seguida foram adicionados $400 \mu \mathrm{L}$ de TRIZOL, $200 \mu \mathrm{L}$ de clorofórmio, homogeneizado e centrifugado a 12000 g por 20 minutos. Após transferirmos a fase aquosa para novo microtubo de $1,5 \mathrm{~mL}$, foi adicionado $1 \mathrm{~mL}$ de isopropanol, homegeneizado e submetido por 30 minutos à temperatura ambiente. Centrifugou-se a $12000 \mathrm{~g}$ por 20 minutos, descartou-se sobrenadante, foram adicionados $500 \mu \mathrm{L}$ de etanol a $75 \%$ e homogeneizado. Posteriormente, foi centrifugado a $7500 \mathrm{~g}$ por 20 minutos, descartado o sobrenadante e deixado para secar por 10-15 minutos e após adicionaram-se $50 \mu \mathrm{L}$ de água livre de RNAse para ressuspensão do RNA. A dosagem do RNA foi feita por NanoDrop ND-1000 UVVis espectrofotômetro (NanoDrop Technologies, Wilmington, DE), com a integridade das amostras demonstrada pelo escore 260/280 (1,8-2,0 foram considerados aceitáveis). 


\subsubsection{Obtenção de cDNA}

A síntese do cDNA foi feita a partir do mRNA com transcriptase reversa (200U/ml) (Invitrogen, USA). A $1000 \mathrm{ng}$ de RNA total em $1 \mu \mathrm{L}$ foram acrescidos 4 $\mu \mathrm{L}$ de High Capacity RNA-to-cDNA Master Mix (Applied Biosystems, USA), $15 \mu \mathrm{L}$ de água livre de RNAse para uma reação final de $20 \mu \mathrm{L}$. A amplificação foi realizada em termociclador (Mastercycler personal, Eppendorf, USA) aos seguintes ciclos: $25^{\circ} \mathrm{C}$ por 5 minutos; 30 minutos por $42^{\circ} \mathrm{C}$; $85^{\circ} \mathrm{C}$ por 5 minutos, $4^{\circ} \mathrm{C}$ hold. As concentrações de cDNA foram acertadas para $1000 \mathrm{ng} / \mu \mathrm{L}$.

\subsubsection{PCR em tempo real para expressão gênica}

Os primers para detecção de PPAR $\alpha$, LPL, CETP e $\beta$-actina (Tabela 1) foram construídos a partir de seqüências do mRNA por ferramentas online disponibilizadas nos sites "Primer 3" (http://frodo.wi.mit.edu) e "Sci Tools" do site "IDTDNA" (http://www.idtdna.com/Scitools) levando-se em conta os critérios para PCR em tempo real, utilizando-se, portanto, primer com 18 a 25 nucleotídeos; com percentagem de $\mathrm{G}+\mathrm{C}$ (guanina+citosina) de ambos os primers entre 40 até $60 \%$ para que a baixa complementaridade entre eles evitasse a formação de dímeros de primers. Utilizamos $10 \mu \mathrm{L}$ de Sybr Green $(2 \mathrm{x})$ (seguindo as instruções do fabricante), primers a $200 \mathrm{nM}$ e 1000 ng de cDNA, com exceção da reação para CETP em que utilizamos $2000 \mathrm{ng} / \mu \mathrm{L}$ de cDNA. A reação foi realizada no aparelho StepOne Plus (Applied Biosystem, USA) em 40 ciclos com as seguintes etapas da reação: $95^{\circ} \mathrm{C}$ por 10 minutos, $95^{\circ} \mathrm{C}$ por 15 segundos, temperatura de anelamento de $57,5-58^{\circ} \mathrm{C}$, por 30 segundos, $70^{\circ} \mathrm{C}$ por 30 segundos, $95^{\circ} \mathrm{C}$ por 15 segundos. A $\beta$ actina foi utilizada como gene endógeno com primers a $150 \mathrm{nM}$ na reação. A expressão relativa de PPAR $\alpha$, CETP e LPL foi quantificada segundo Pfaffl et al (2001). 
Tabela 1- Sequência de iniciadores (primers) com número de acesso, temperatura de anelamento e tamanho do produto amplificado

\begin{tabular}{|c|c|c|c|c|}
\hline Primer & Sequência & $\begin{array}{l}\text { Número de } \\
\text { acesso }\end{array}$ & $\begin{array}{c}\text { Temperatura } \\
\text { de } \\
\text { anelamento } \\
\left({ }^{\circ} \mathrm{C}\right) \\
\end{array}$ & $\begin{array}{c}\text { Tamanho } \\
\text { do } \\
\text { produto } \\
\text { (pb) }\end{array}$ \\
\hline $\begin{array}{l}\text { PPAR- } \\
\text { alfa }\end{array}$ & $\begin{array}{l}\text { Senso 5' CCTACCTGAAGAACTTCAACATGA 3' } \\
\text { Antisenso:5' GGTCTCCATGTCATGTATAACGAA 3' }\end{array}$ & AJ555631.1 & 57,5 & 101 \\
\hline CETP & $\begin{array}{l}\text { Senso: 5' AGGTGGCTTTGACAACCCTCATTA 3' } \\
\text { Anti-senso: 5' AGTCCATCTGTAGCAGCAGGAAGC 3' }\end{array}$ & M63992.1 & 58 & 105 \\
\hline LPL & $\begin{array}{l}\text { Senso: 5' GTATCTAACTGCCACTTCAACCAC 3' } \\
\text { Anti-senso: 5' CAACTCTCATACATTCCTGTCACC 3' }\end{array}$ & AB194713.1 & 58 & 83 \\
\hline $\begin{array}{l}\text { Beta- } \\
\text { actina }\end{array}$ & $\begin{array}{l}\text { Senso: 5' CTTCCTTCCTGGGTATGGAATCCT 3' } \\
\text { Antisenso: 5' CAGACAGCACTGTGTTGGCATAGA 3' }\end{array}$ & AJ312092 & $57,5-58$ & 103 \\
\hline
\end{tabular}

\subsection{Análise estatística}

A análise estatística foi realizada empregando-se testes não paramétricos Kruskal Wallis e pós-teste de Dunn ou de Mann-Whitney utilizando-se, para a apresentação dos resultados, a mediana e percentis de $25 \%$ e $75 \%$. O nível de significância foi estabelecido em $5 \%$. 


\section{RESULTADOS}

\subsection{Perfil lipídico durante a evolução de leishmaniose visceral em hamster}

Ao avaliarmos as alterações do perfil lipídico nos hamsteres com LV com 30, 55 e 90 dias de infecção, observamos que com 30 dias de infecção ocorreu tendência de aumento dos níveis de triglicérides nos infectados, e nos hamsteres com 55 e 90 dias de infecção houve aumento significante destes níveis quando comparados aos controles (Figura 1).

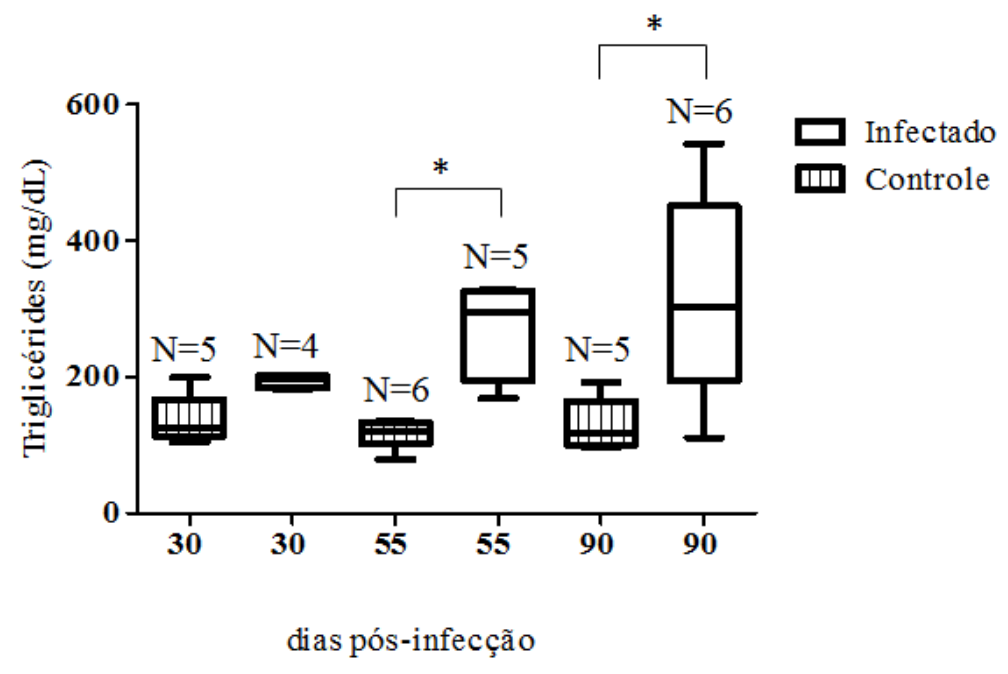

Figura 1- Concentração de triglicérides (mediana e percentis de $25 \%$ e $75 \%$ ) no plasma de hamsteres controles e infectados aos 30,55 e 90 dias de infecção. Os hamsteres foram infectados intraperitonealmente com $2 \times 10^{7}$ amastigotas de $L$. (L.) infantum. ${ }^{*} \mathrm{p} \leq 0,05$ (Testes de Kruskal Wallis e de Dunn).

Nos hamsteres com 30, 55 e 90 dias de infecção não observamos aumento significante dos níveis plasmáticos de colesterol total em comparação aos controles. Observamos uma tendência de aumento aos 90 dias de infecção (Figura 2). 


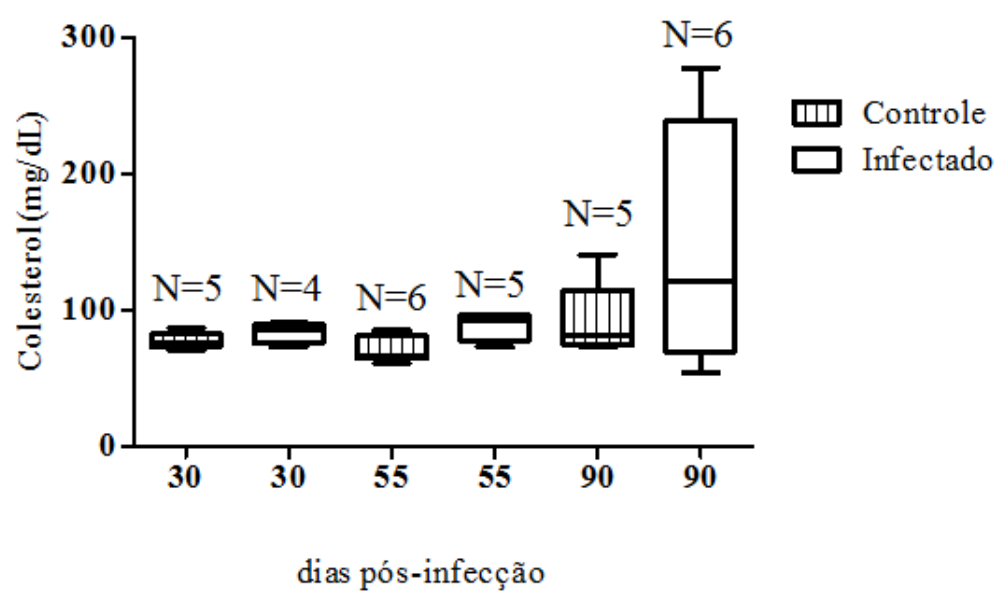

Figura 2- Concentração de colesterol total (mediana e percentis de $25 \%$ e $75 \%$ ) no plasma de hamsteres controles e infectados aos 30, 55 e 90 dias de infecção. Os hamsteres foram infectados intraperitonealmente com $2 \times 10^{7}$ amastigotas de $L$. (L.) infantum.

Quando avaliamos os níveis de HDL plasmáticos, observamos que não houve diferença significante entre os animais infectados e os sadios nos respectivos períodos testados. No entanto, ocorreu tendência de redução de HDL tanto nos infectados como nos controles de 90 dias de infecção, proporcionalmente (Figura 3).

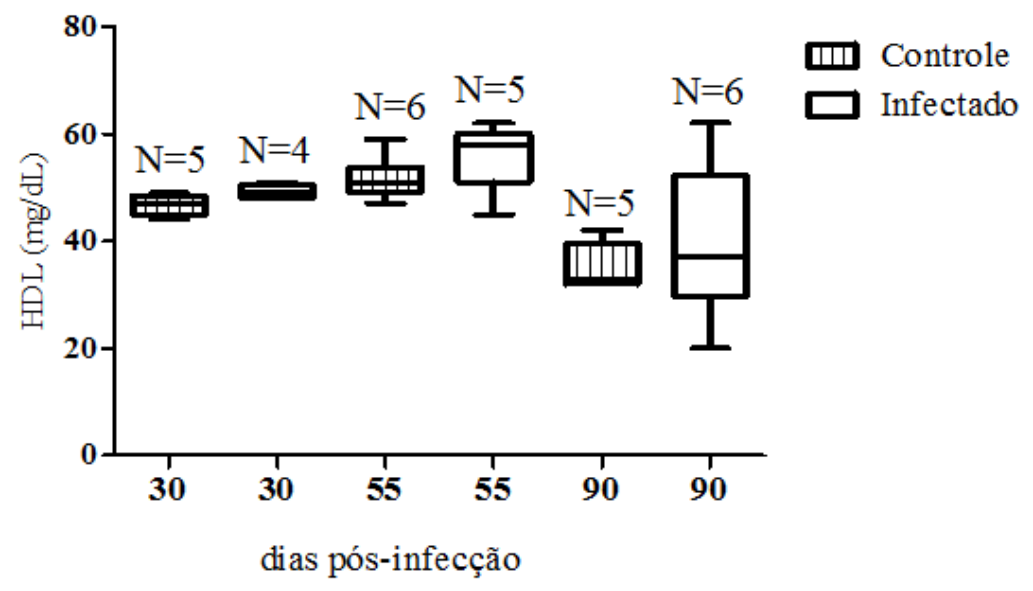

Figura 3- Concentração de HDL (mediana e percentis de $25 \%$ e $75 \%$ ) no plasma de hamsteres controles e infectados aos 30,55 e 90 dias de infecção. Os hamsteres foram infectados intraperitonealmente com $2 \times 10^{7}$ amastigotas de $L$. (L.) infantum. 
5.2 Avaliação da expressão de mRNA de PPARa, CETP e LPL por qPCR na leishmaniose visceral em hamster

Na padronização da expressão relativa de mRNA $(\Delta \mathrm{CT})$ de PPAR $\alpha$, CETP e LPL, os gráficos de dissociação da temperatura de melting, para o gene de PPAR $\alpha$, CETP, LPL e $\beta$-actina, revelaram um pico único apenas em uma temperatura $\left(79^{\circ} \mathrm{C}, 82^{\circ} \mathrm{C}, 78^{\circ} \mathrm{C}\right.$ e $79^{\circ} \mathrm{C}$, respectivamente), demonstrando a amplificação correta do gene alvo sem produtos inespecíficos (Figura 4). 

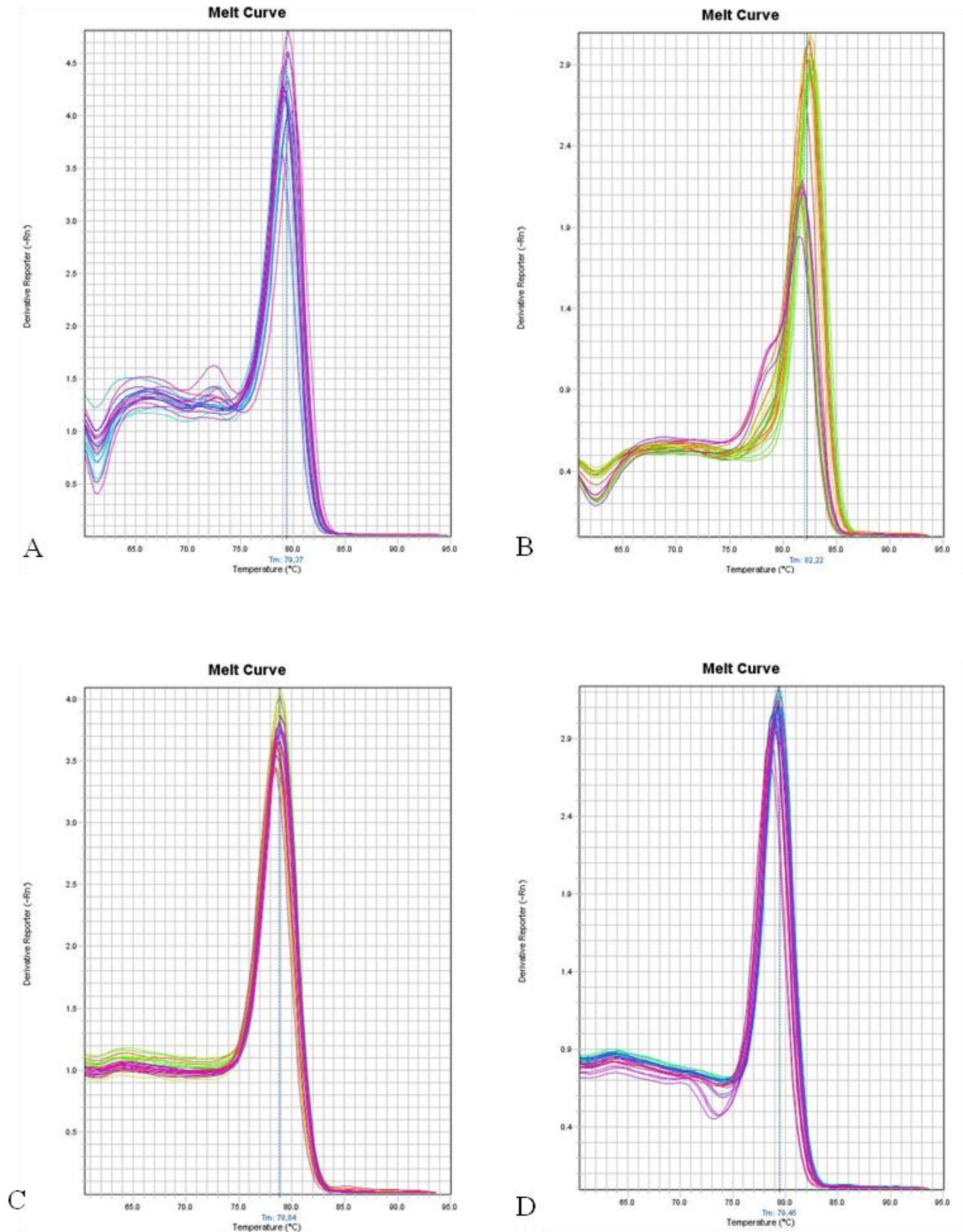

Figura 4- Curva de melting dos produtos amplificados por qPCR de PPAR $\alpha$ (A), CETP (B), LPL (C) e $\beta$-actina (D).

Para avaliar a expressão de mRNA de PPAR $\alpha$, CETP e LPL utilizamos amostras de hamsteres apenas com 55 e 90 dias de infecção, já que os hamsteres com 30 dias pós-infecção não apresentaram alterações significantes do perfil lipídico. A expressão de mRNA de PPAR $\alpha$ no fígado dos animais infectados apresentou tendência à redução em relação aos controles com 90 dias pós-infecção (Figura 5). 
A

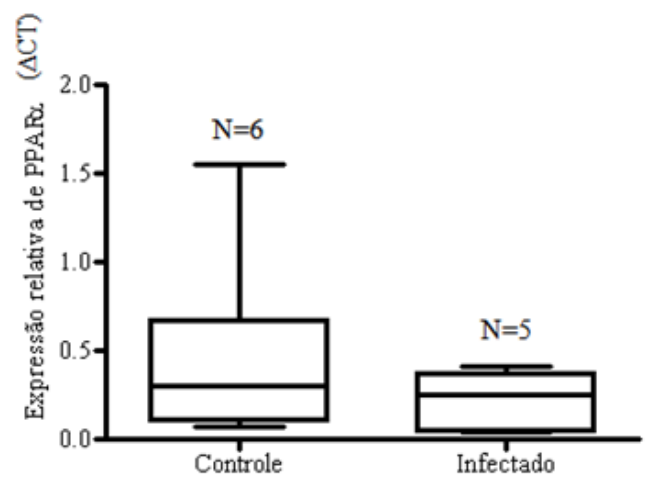

B

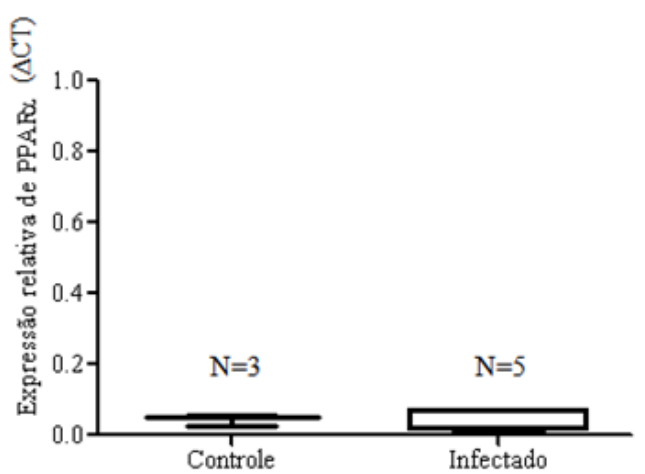

Figura 5- Expressão relativa $(\Delta \mathrm{CT})$ de mRNA de PPAR $\alpha$ calculada em relação a expressão de mRNA de $\beta$-actina ( $\triangle \mathrm{CT}$ ) no fígado de hamsteres com 55 (A) e 90 dias (B) de infecção (mediana e percentis de $25 \%$ e $75 \%$ ). Os hamsteres foram infectados intraperitonealmente com $2 \times 10^{7}$ amastigotas de L. (L.) infantum.

Na avaliação da expressão de CETP utilizamos fragmentos de fígado de hamsteres com 55 dias de infecção. Nestes observamos redução significante da expressão de mRNA de CETP comparando com os controles (Figura 6). Entretanto, no fígado de hamsteres com 90 dias pós-infecção houveram amplificações inespecíficas que impossibilitaram a realização da estatística. Acreditamos que isto tenha ocorrido devido a baixa expressão de CETP no fígado intrínseca a este animal (Jiang et al, 1991). 


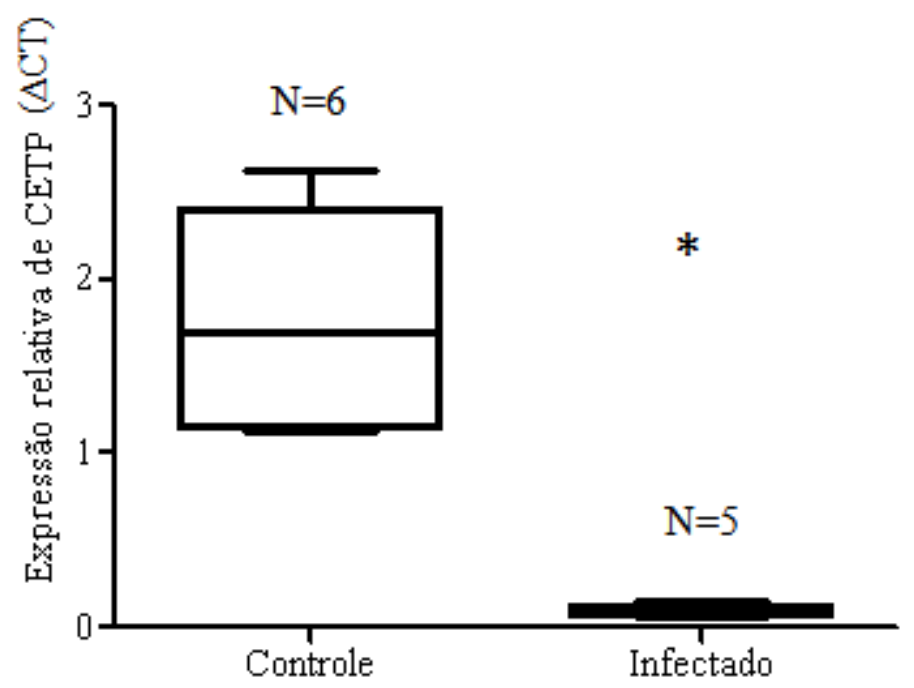

Figura 6- Expressão relativa $(\Delta \mathrm{CT})$ de mRNA de CETP foi calculada em relação a expressão de mRNA de $\beta$-actina $(\Delta \mathrm{CT})$ no fígado de hamsteres com 55 dias de infecção (mediana e percentis de $25 \%$ e $75 \%$ ). Os hamsteres foram infectados intraperitonealmente com $2 \times 10^{7}$ amastigotas de $L$. (L.) infantum. * $\mathrm{p} \leq 0,05$ (Teste de Mann-Whitney).

Na avaliação da expressão de mRNA de LPL não realizamos coleta de fragmentos de coração nos hamsteres com 55 dias pós-infecção somente naqueles com 90 dias pós-infecção. Após a eutanásia dos infectados por 55 dias, observamos na literatura que a expressão de LPL no fígado de hamsteres era baixa e elevada no coração, e ao tentarmos avaliar a expressão de LPL no figado não ocorreu amplificação, sendo diferente do que foi observado com as alíquotas de coração.

Ao avaliarmos a expressão de mRNA de LPL no coração dos hamsteres infectados por 90 dias houve uma redução significante em comparação aos controles (Figura 7). 


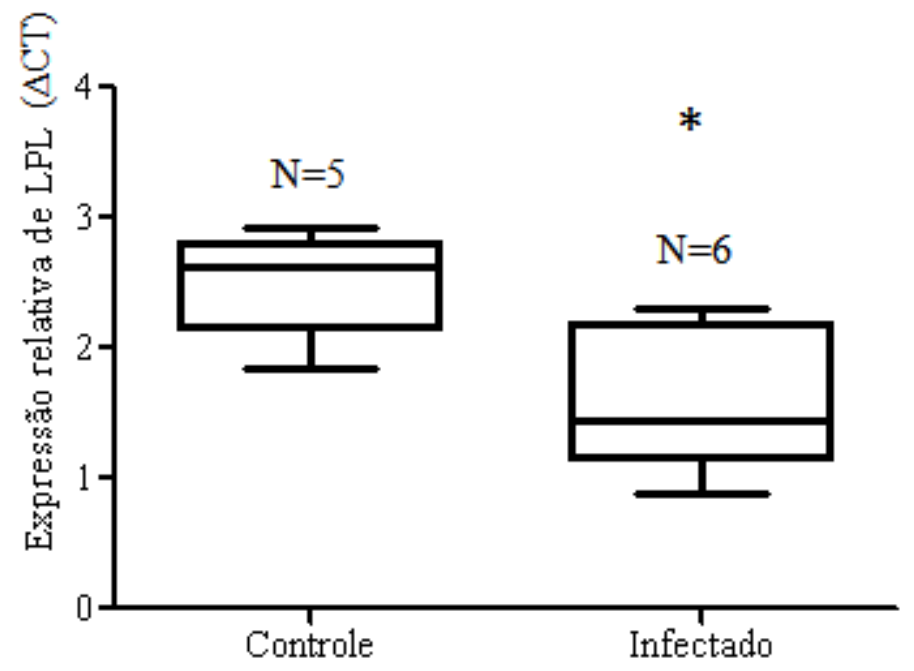

Figura 7- Expressão relativa $(\Delta \mathrm{CT})$ de mRNA de LPL foi calculada em relação a expressão de mRNA de $\beta$-actina $(\Delta \mathrm{CT})$ no coração de hamsteres com 90 dias de infecção (mediana e percentis de $25 \%$ e $75 \%$ ). Os hamsteres foram infectados intraperitonealmente com $2 \times 10^{7}$ amastigotas de $L$. (L.) infantum. * $\mathrm{p} \leq 0,05$ (Teste de Mann-Whitney).

\subsection{Efeito do tratamento com ciprofibrato nos níveis de lipoproteínas e na carga parasitária}

Para avaliarmos o efeito do ciprofibrato no perfil lipídico e na carga parasitária de hamster com LV, tratamos os animais com ciprofibrato nas doses de 19,3, 76, 250 e $500 \mathrm{mg} / \mathrm{kg}$ de peso por 15 dias e eutanásia com 75 dias pós-infecção. No entanto, houve efeito colateral com as doses de 76, 250 e $500 \mathrm{mg} / \mathrm{Kg}$ nos hamsteres com edema subcutâneo de grau avançado e por questão ética estes foram eutanasiados no dia subsequente à constatação dessa manifestação. A dose de 19,3 $\mathrm{mg} / \mathrm{Kg}$ de ciprofibrato gerou redução das alterações lipoprotéicas como esperado sem causar efeitos colaterais, o que nos levou a selecionar esta dose para um experimento final com 10 dias de tratamento e eutanásia com 55 dias de infecção.

Ao avaliarmos o perfil lipídico, os níveis de triglicérides nos animais infectados não tratados, aumentaram de forma significante quando comparados aos controles não tratados. Os níveis de triglicérides nos hamsteres infectados, tratados com ciprofibrato, reduziram significantemente em relação aos infectados não tratados (Figura 8). 


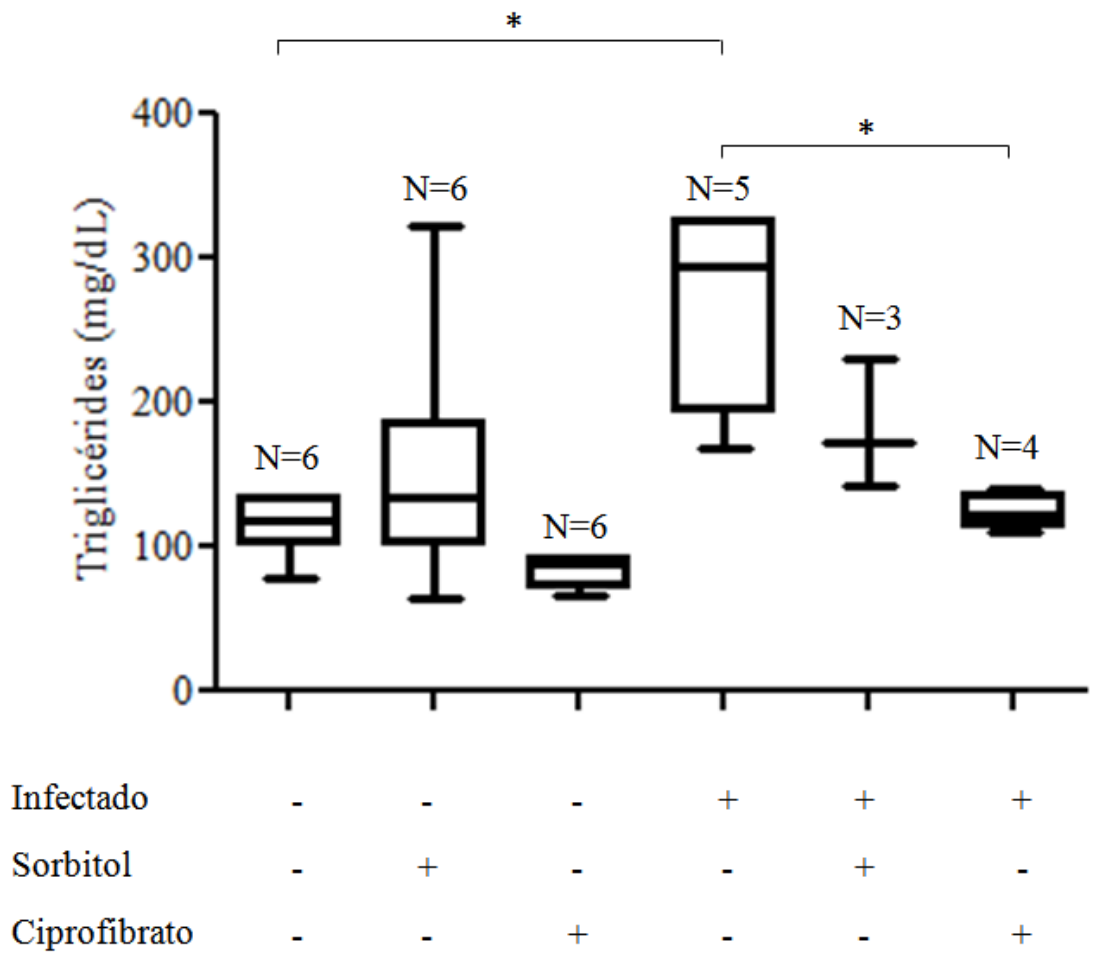

Figura 8- Concentração de triglicérides (mediana e percentis de $25 \%$ e $75 \%$ ) no plasma de hamsteres infectados e não infectados, com e sem tratamento com sorbitol ou ciprofibrato $(19,3 \mathrm{mg} / \mathrm{Kg})$ com 55 dias pós-infecção. Os hamsteres foram infectados intraperitonealmente com $2 \times 10^{7}$ amastigotas de L. (L.) infantum. * $\mathrm{p} \leq 0,05$ (Testes de Kruskal Wallis e de Dunn).

Nos hamsteres infectados não tratados comparados aos controles não tratados observamos tendência de aumento do colesterol total. Já naqueles que foram infectados e tratados com ciprofibrato, constatamos redução significante dos níveis de colesterol quando comparados aos infectados não tratados (Figura 9). 


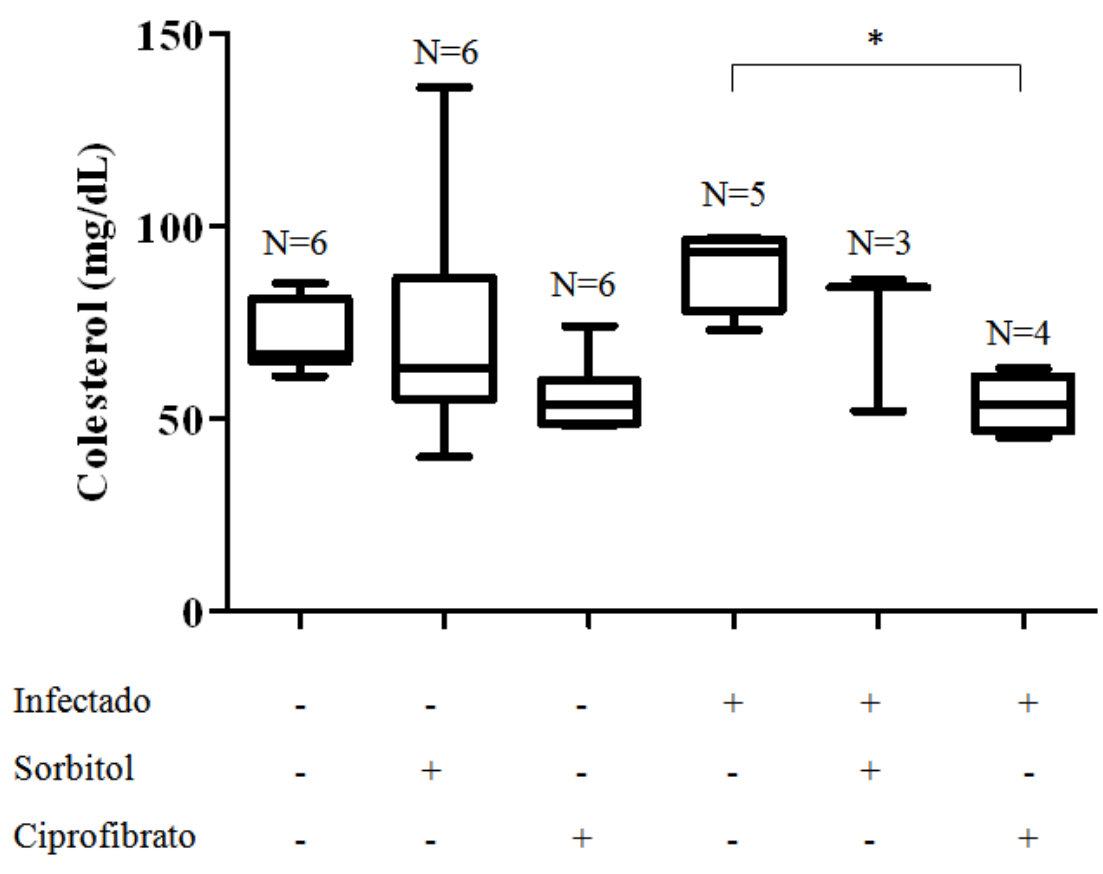

Figura 9- Concentração de colesterol total (com mediana e percentis de $25 \%$ e $75 \%$ ) no plasma de hamsteres infectados e não infectados, com e sem tratamento com sorbitol ou ciprofibrato $(19,3 \mathrm{mg} / \mathrm{Kg})$ com 55 dias pós-infecção. Os hamsteres foram infectados intraperitonealmente com $2 \times 10^{7}$ amastigotas de $L$. (L.) infantum. * $\mathrm{p} \leq 0,05$ (Testes de Kruskal Wallis e de Dunn).

Os níveis de HDL em hamster não elevaram significantemente com o tratamento com 19,3 mg/Kg de ciprofibrato, pois estes apresentaram o oposto, ou seja, tendência à redução. Os níveis de HDL foram similares entre os hamsteres infectados não tratados e os controles não tratados (Figura 10). 


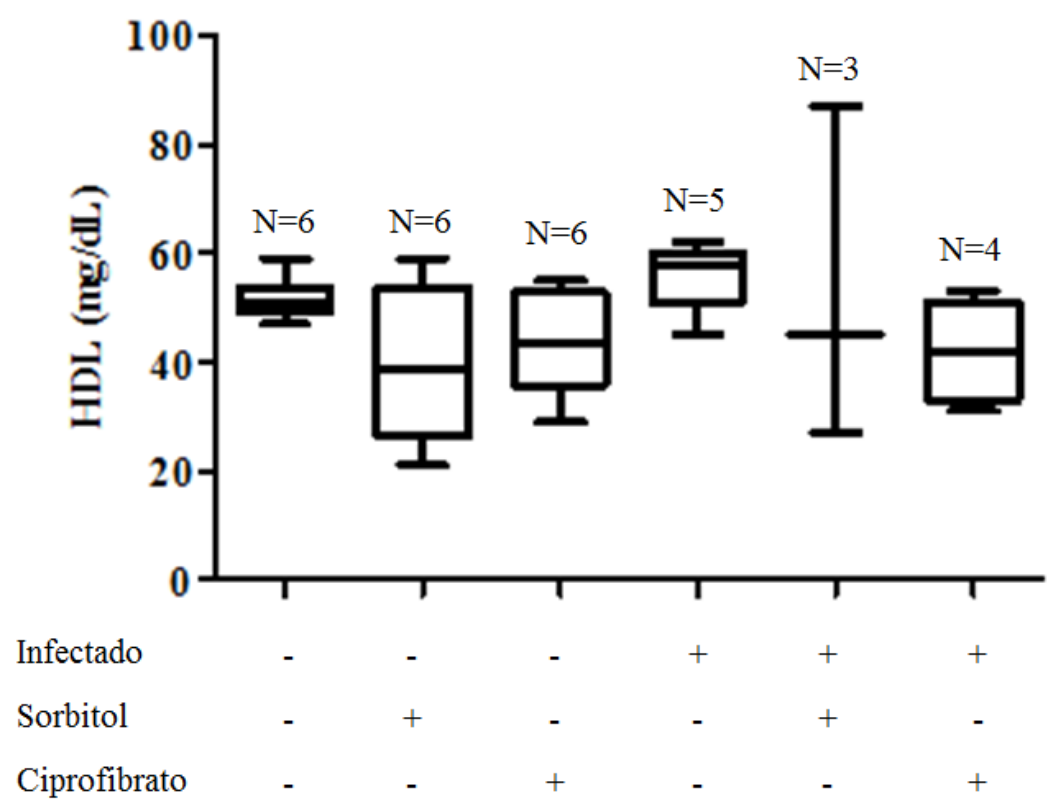

Figura 10- Concentração de HDL (com mediana e percentis de $25 \%$ e $75 \%$ ) no plasma de hamsteres infectados e não infectados, com e sem tratamento com sorbitol ou ciprofibrato $(19,3 \mathrm{mg} / \mathrm{Kg})$ com 55 dias pós-infecção. Os hamsteres foram infectados intraperitonealmente com $2 \times 10^{7}$ amastigotas de $L$. (L.) infantum.

\subsubsection{Avaliação da carga parasitária}

Nos animais com 55 dias pós-infecção, nos quais avaliamos o efeito do tratamento com ciprofibrato no perfil lipídico, também, analisamos a carga parasitária. Não observamos redução da carga parasitária no baço e fígado por microscopia óptica com este tratamento (Figura 11). 

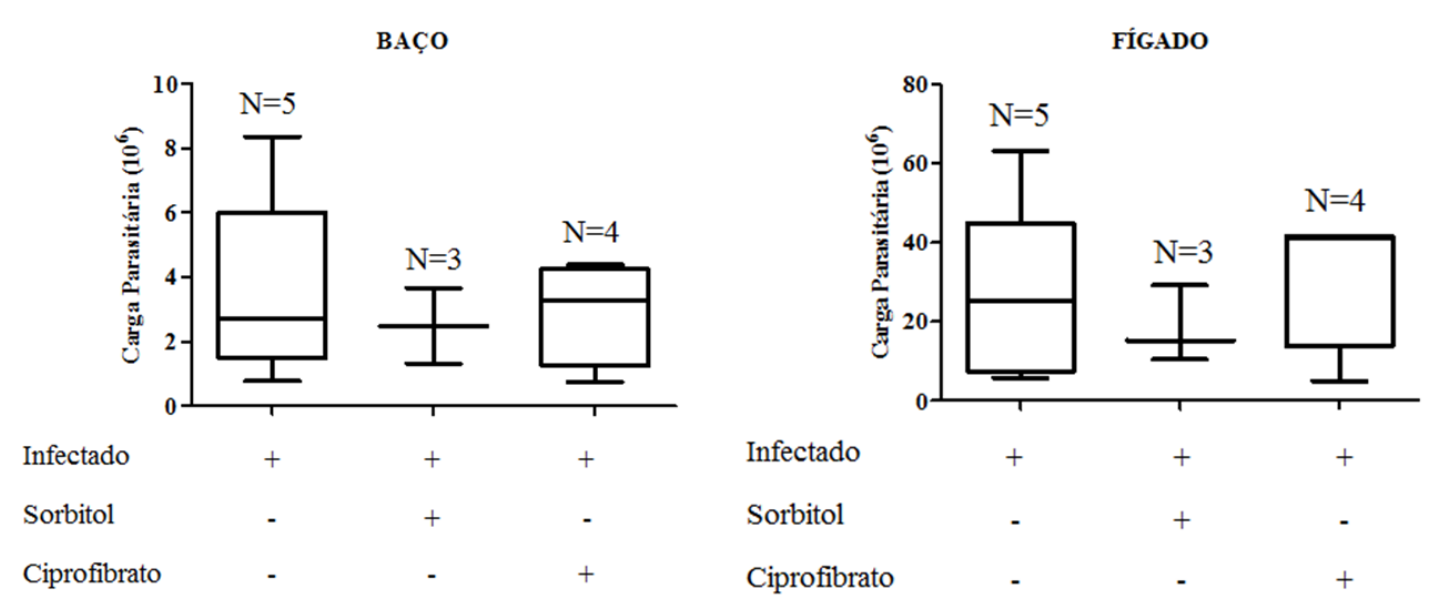

Figura 11- Carga parasitária (com mediana e percentis de $25 \%$ e $75 \%$ ) por microscopia óptica no baço e fígado de hamsteres infectados sem tratamento, tratados com sorbitol e tratados com ciprofibrato $(19,3 \mathrm{mg} / \mathrm{Kg})$ com 55 dias pós-infecção. Os hamsteres foram infectados intraperitonealmente com $2 \times 10^{7}$ amastigotas de $L$. (L.) infantum. 


\section{DISCUSSÃO}

Diversos estudos desenvolvidos com LV em diferentes modelos animais de experimentação foram utilizados, como os camundongos que desenvolvem infecção aguda, mas são capazes de controlar a infecção (Murray et al, 1987; Barbosa Júnior et al, 1987); os cães, como vetor da doença peri-urbano, desenvolvem a LV com manifestações clínicas similares ao homem com exceção das alterações da pele que não são observadas no humano. Além disso, a evolução da infecção pode ser muito prolongada e variável (Abranches et al, 1991; Pinelli et al, 1995) dificultando seu uso como modelo experimental. Desta forma, o hamster se constitui como a melhor opção dentre estas espécies animais, pois desenvolve infecção progressiva e em menor tempo semelhante à humana.

Em análises de metabolismo lipídico, o hamster constitui também um bom modelo para avaliação, desenvolvendo dislipidemia (hipertrigliceridemia, hipercolesterolemia) e formação de placa aterosclerótica similarmente à humana quando submetido à dieta hiperlipidêmica (Nistor et al, 1987; Sullivan et al, 1993).

O metabolismo lipoprotéico do hamster é similar ao do homem com LDL como principal lipoproteína carreadora de colesterol e produção no fígado de VLDL contendo apo B-100 com densidade semelhante (Arbeeny et al, 1992; Sullivan et al, 1993). Em contraposição, o rato apresenta secreção no fígado de VLDL contendo apo B-48 e apo B-100, entretanto, no homem, as partículas de VLDL são compostas apenas por apo B-100. Além disso, rato e camundongo não apresentam expressão da CETP (Arbeeny et al, 1992; Ha e Barter, 1982; Sparks et al, 1981). Como os camundongos apresentam componentes diferentes dos humanos em relação ao metabolismo lipídico, tem sido geneticamente manipulados para estudos de mecanismos patogênicos envolvendo alterações lipídicas, sendo as modificações voltadas a genes de várias apolipoproteínas, LPL, lipase hepática, CETP, LCAT, receptores de LDL, de quilomícrons remanescentes e de scavenger. A manipulação genética nesses casos tem o intuito de reduzir ou elevar a expressão destes alvos neste modelo (Breslow, 1993). Concluímos que podemos considerar o hamster como 
um modelo mais adequado para avaliação lipídica, pela semelhança ao homem e sem necessidade de manipulações genéticas.

Com relação às alterações do perfil lipídico em diferentes hospedeiros na LV, a literatura demonstra que diferem quanto ao perfil, porém, apontam que estas ocorrem principalmente com aumento dos níveis de triglicérides e redução da HDL (Agouridis et al, 2012; Bekaert et al, 1989; Durgut et al, 2012; Lal et al, 2007; Nieto et al, 1992; Soares et al, 2010). No presente trabalho, ao avaliarmos os níveis lipoprotéicos em hamster após os períodos de 30, 55 e 90 dias de infecção, observamos aumento de triglicérides, porém, contrapondo os dados da literatura, não observamos redução da HDL.

Em um trabalho realizado com camundongos BALB/c infectados com $L$. (L.) donovani mostrou redução dos níveis de triglicérides nos períodos de 8,15 e 30 dias pós-infecção e com 60 dias os animais recuperaram os níveis similarmente ao período anterior à infecção (Ghosh et al, 2013), porém, é importante ressaltar que camundongo é naturalmente resistente à infecção enquanto que o hamster é susceptível, o que pode explicar as diferenças das alterações lipídicas. Por outro lado, em estudos desenvolvidos em pacientes reportados com LV e em hamsteres infectados houve aumento significante dos níveis de triglicérides, corroborando com o presente estudo (Agouridis et al, 2012; Bekaert et al, 1989; Lal et al, 2007; Vasconcelos et al, 1996).

Durgut e colaboradores (2012), estudando cães com LV detectaram aumento do colesterol, sendo similar ao que observamos no presente trabalho com tendência de aumento do colesterol nos infectados. Em outros trabalhos realizados em pacientes com LV e em modelos murinos, no entanto, os níveis de colesterol total estavam reduzidos (Lal et al, 2010; Liberopoulos et al, 2002; Ghosh et al, 2013). Talvez esta diferença esteja relacionada ao perfil lipídico intrínseco de cada espécie.

Tanto em pacientes como em cães com LV em relação aos seus controles foi observada redução da HDL (Nieto et al, 1992; Soares et al, 2010). Assim como no caso clínico comentado por Agouridis et al (2012), no qual o indivíduo com diagnóstico de LV apresentou HDL severamente reduzida, e após ser tratado com anfotericina B em associação com rosuvastatina (droga hipolipemiante), houve melhora no quadro de infecção como também dos níveis lipídicos. Corroborando 
com estes dados, Ottoni (2010), em seu estudo com indivíduos com LV apresentaram redução da HDL, assim como naqueles com reação de Montenegro positiva ou negativa sem histórico de LV e os que tiveram histórico pregresso da LV, sendo contrário aos dados obtidos no presente estudo.

A partir das alterações das lipoproteínas observadas em nosso estudo, avaliamos PPARa, CETP e LPL como fatores que possam elucidar os dados encontrados. Na análise da expressão de mRNA de PPAR $\alpha$ e CETP utilizamos o fígado por ser um órgão associado tanto ao metabolismo lipídico como um dos sítios alvo da infecção pela $L$. (L.) infantum. E para LPL optamos pelo coração, já que não é possível detectá-la no fígado de roedores adultos, somente sendo detectada em neonatos (Semenkovich et al, 1989; Yacoub et al, 1990). Levando-se em conta o perfil natural da expressão dos alvos acimas citados, no hamster, Jiang e colaboradores (1991), demonstraram alta expressão da LPL e da CETP nos tecidos adiposo, cardíaco e muscular esquelético com baixa expressão no fígado. Em contraposição, no humano há predominância da expressão da CETP no fígado, baço e tecido adiposo, com baixa expressão no rim, adrenal, músculo esquelético e coração (Tall, 1995). No rato adulto foi observada alta expressão de PPAR $\alpha$ no fígado, rim, retina, estômago e intestino delgado (Braissant et al, 1996); em concordância com a expressão de PPAR $\alpha$ no fígado de humano que é elevada, além dos tecidos cardíaco, renal, intestino grosso e muscular esquelético (Auboeuf et al, 1997). Já à expressão da LPL em rato foi elevada no tecido adiposo, fígado, coração, glandulas mamárias, macrófago e cérebro (Schoonjans et al, 1996).

No que se refere a influência destes fatores em doenças metabólicas, em alguns estudos pôde-se observar o aumento da expressão da CETP em presença de dieta hiperlipidêmica em humano, coelho e camundongo (Quinet et al, 1990; Masucci-Magoulas, 1996; Tall, 1995). Em hamster submetido à dieta similar ocorreu aumento da expressão da CETP nos tecidos adiposo, cardíaco e muscular esquelético, entretanto, não houve alteração equivalente da expressão da LPL (Jiang et al, 1991). Jeong e colaboradores (2004) e Srivastava e colaboradores (2006) demonstraram que o uso de fenofibrato (que ativa PPAR $\alpha$ ) foi capaz de prevenir a obesidade e a hipertrigliceridemia em camundongos com deficiência do receptor da LDL. Outro fator analisado foi que a deficiência da LPL em humanos gerou 
hipertrigliceridemia grave e está associada a doenças como diabetes do tipo II, evolução da coronariopatia cardíaca, hipertensão arterial e doença de Alzheimer (Xie et al, 2010).

Segundo Ottoni (2010), com o intuito de determinar a expressão de PPAR $\alpha$ em indivíduos com LV associados as alterações lipoprotéicas, observou que a expressão foi cerca de 21 vezes menor do que naqueles sem histórico de LV e com teste de Montenegro negativo. Os níveis de triglicérides foram elevados e de colesterol total e HDL foram reduzidos naqueles indivíduos com LV. Estes dados se assemelham ao presente trabalho com a tendência de redução da expressão de PPAR $\alpha$ e aumento de triglicérides. Indicando provavelmente que a inibição de PPAR $\alpha$, por consequência também iniba LPL, contribuindo assim para o aumento de triglicérides.

Segundo Grion et al (2010), em pacientes com septicemia houve redução da expressão da CETP quando estes foram comparados aos controles. Em um quadro clínico de sepse foi constatada a resistência à insulina, aumento de triglicérides, redução de HDL e LDL (Rossi et al, 2007). Assim como em pesquisa com hamster e endotoxinas, observou-se que estas estimularam redução rápida e progressiva de expressão da CETP no soro, e nos tecidos adiposo, cardíaco e muscular (Hardardóttir et al, 1996). Nestes estudos os níveis lipoprotéicos foram alterados com aumento de triglicérides e redução de HDL associados à redução da CETP. Estes dados demonstram similaridade ao que observamos no presente trabalho com aumento de triglicérides e redução da expressão da CETP na LV. Entretanto, a expressão da CETP cardíaca não pode ser extrapolada como parâmetro de sítio de infecção na leishmaniose visceral, além disso, o coração apresenta menor importância no metabolismo lipídico do que o fígado.

Em continuidade com estes alvos lipídicos, utilizando-se LPL bovina em cultura com vírus da hepatite C, Maillard e colaboradores (2011) constataram que a LPL inibiu à infecção. Camundongos submetidos à endotoxinas apresentaram atividade da LPL reduzida em tecido adiposo. Nos camundongos resistentes à endotoxinas não ocorreu à redução da atividade como naqueles que foram sensíveis (Kawakami e Cerami, 1981), indicando agravamento da infecção com a redução da atividade da LPL. 
No estudo desenvolvido por Sammalkorpi et al (1988) em indivíduos com infecções agudas, também foi observada a redução da atividade da LPL com aumento de triglicérides e colesterol total e redução da HDL, similarmente aos nossos achados com redução da expressão da LPL e aumento de triglicérides.

É interessante ressaltar que observamos aumento de triglicérides e redução da expressão de mRNA da CETP e da LPL na LV em hamster corroborando com os dados da literatura em diferentes processos infecciosos. A redução da expressão destes dois alvos nos chama a atenção, pois estão diretamente relacionados ao transporte de TG e esta foi à fração lipídica mais afetada no curso da infecção. Provavelmente, CETP e LPL sejam os principais alvos durante a progressão da LV. A LPL é uma enzima chave no metabolismo de lipoproteínas ricas em TG e possui importante papel no controle da geração de ácidos graxos (Schoonjans et al, 1996), sendo então, mais intensamente responsável pelo controle metabólico de TG. Não observamos na literatura nenhum estudo realizado avaliando-se evolutivamente as alterações lipoprotéicas e a expressão de mRNA de PPAR $\alpha$, CETP e LPL associados a LV em hamster, porém, pelos dados que coletamos podemos considerar a necessidade de avaliação do papel do metabolismo lipídico na LV.

Com base nestes dados, avaliamos o uso da droga ciprofibrato no controle das alterações lipídicas e da carga parasitária. A utilização do tratamento com ciprofibrato na dose de $19,3 \mathrm{mg} / \mathrm{Kg}$ gerou o controle das alterações lipoprotéicas com redução de triglicérides e de colesterol total no hamster infectado, demonstrando o efeito hipolipemiante da droga, entretanto, observamos que não ocorreu aumento significante dos níveis de HDL, sugerindo diferenças de metabolismo entre hamster e humano. Alguns estudos apontam redução da expressão de mRNA de apo A-I e apo A-II (principais componentes da HDL) em roedores tratados com fibratos, o que poderia explicar a tendência de redução dos níveis de HDL nos hamsteres infectados tratados com esta droga no presente estudo (Berthou et al, 1995; Staels et al, 1992).

Em relação à carga parasitária, observamos que não foi reduzida com o tratamento, apesar da redução das alterações lipoprotéicas no hamster. Talvez este resultado contraditório a nossa hipótese em relação ao efeito da droga tenha ocorrido devido ao tempo de infecção, dose de ciprofibrato, modelo animal estudado, virulência parasitária e espécie do parasito. Também pode significar que o parasito 
possa desenvolver outro mecanismo de escape para sua sobrevivência, substituindo lípides por proteínas para geração de energia. 


\section{CONCLUSÃO}

O hamster pode ser considerado um bom modelo para avaliação da alteração do metabolismo lipídico na leishmaniose viseral.

A infecção ativa por $L$. (L.) infantum levou a alterações das frações lipoprotéicas com aumento de TG, sendo este o principal achado, porém, não ocorreu alteração dos níveis de HDL e nem de colesterol total.

Na infecção também houve redução da expressão de mRNA da LPL e da CETP que sugere-se determinar as alterações dos níveis de liproteínas encontradas, principalmente de triglicérides, pois estes dois alvos estão diretamente relacionados a regulação do metabolismo de TG;

Houve tendência de redução da expressão de mRNA de PPAR $\alpha$ nos infectados o que auxilia na baixa expressão da LPL observada, já que PPAR $\alpha$ é responsável por ativá-la.

O tratamento com ciprofibrato na dose de $19,3 \mathrm{mg} / \mathrm{Kg}$ foi capaz de reduzir os níveis de triglicérides e colesterol total nos hamsteres infectados, entretanto, não gerou aumento de HDL;

O tratamento com esta droga também não determinou a redução da carga parasitária no baço e no fígado. 


\section{REFERÊNCIAS}

Abranches P, Santos-Gomes G, Rachamim N, Campino L, Schnur LF, Jaffe CL. An experimental model for canine visceral leishmaniasis. Parasite Immunol. 1991 Sep;13(5):537-50.

Agouridis AP, Liberopoulos EN, Kostapanos MS, Elisaf MS. New-onset extremely low levels of high-density lipoprotein cholesterol. J Clin Lipidol. 2012 NovDec;6(6):593-5.

Auboeuf D, Rieusset J, Fajas L, Vallier P, Frering V, Riou JP, et al. Tissue distribution and quantification of the expression of mRNAs of peroxisome proliferatoractivated receptors and liver $\mathrm{X}$ receptor-alpha in humans: no alteration in adipose tissue of obese and NIDDM patients. Diabetes. 1997 Aug; 46(8):1319-27.

Arbeeny CM, Meyers DS, Bergquist KE, Gregg RE. Inhibition of fatty acid synthesis decreases very low density lipoprotein secretion in the hamster. J Lipid Res. 1992 Jun;33(6):843-51.

Bansal D, Bhatti HS, Sehgal R. Role of cholesterol in parasitic infections. Lipids Health Dis. 2005 May;4(10):1-7.

Bañuls AL, Hide M, Prugnolle F. Leishmania and the leishmaniases: a parasite genetic update and advances in taxonomy, epidemiology and pathogenicity in humans. Adv Parasitol. 2007;64:1-109.

Barbosa Júnior AA, Andrade ZA, Reed SG. The pathology of experimental visceral leishmaniasis in resistant and susceptible lines of inbred mice. Braz J Med Biol Res. 1987;20(1):63-72.

Bekaert ED, Kallel R, Bouma ME, Lontie JF, Mebazaa A, Malmendier CL, et al. Plasma lipoproteins in infantile visceral leishmaniasis: deficiency of apolipoproteins A-I and A-II. Clin Chim Acta. 1989 Sep;184(2):181-91.

Berthou L, Saladin R, Yaqoob P, Branellec D, Calder P, Fruchart JC, et al. Regulation of rat liver apolipoprotein A-I, apolipoprotein A-II and acyl-coenzyme A oxidase gene expression by fibrates and dietary fatty acids. Eur J Biochem. 1995 Aug;232(1):179-87. 
Braissant O, Foufelle F, Scotto C, Dauça M, Wahli W. Differential expression of peroxisome proliferator-activated receptors (PPARs): tissue distribution of PPARalpha, -beta, and -gamma in the adult rat. Endocrinology. 1996 Jan;137(1):354-66.

Brasil. Ministério da Saúde. Secretaria de Vigilância em Saúde. Guia de vigilância epidemiológica/Ministério da Saúde, Secretaria de Vigilância em Saúde, Departamento de Vigilância Epidemiológica. 7. ed. Brasília (DF): Ministério da Saúde, 2009. 816p. Disponível em: http://portal.saude.gov.br/portal/arquivos/pdf/gve7edwebatual.pdf

Breslow JL. Transgenic mouse models of lipoprotein metabolism and atherosclerosis. Proc Natl Acad Sci U S A. 1993 Sep;90(18):8314-8.

Cazita PM, Barbeiro DF, Moretti AI, Quintão EC, Soriano FG. Human cholesteryl ester transfer protein expression enhances the mouse survival rate in an experimental systemic inflammation model: a novel role for CETP. Shock. 2008 Nov;30(5):590-5.

Chakraborty D, Banerjee S, Sen A, Banerjee KK, Das P, Roy S. Leishmania donovani affects antigen presentation of macrophage by disrupting lipid rafts. J Immunol. 2005 Sep;175(5):3214-24.

de Gottardi A, Pazienza V, Pugnale P, Bruttin F, Rubbia-Brandt L, Juge-Aubry CE, et al. Peroxisome proliferator-activated receptor-alpha and -gamma mRNA levels are reduced in chronic hepatitis $\mathrm{C}$ with steatosis and genotype 3 infection. Aliment Pharmacol Ther. 2006 Jan;23(1):107-14.

Durgut R, Dalkilinç D, Guzel M. Evaluation of the Serum Lipid Profiles in Dogs with Symptomatic Visceral Leishmaniasis. Kafkas Univ Vet Fak Derg. 2012;18(4):585-588.

Fiegenbaum M, Hutz MH. Farmacogenética de fármacos hipolipemiantes. Medicina, Ribeirão Preto. 2006 out/dez;39(4):543-53.

Forte TM, Goth-Goldstein R, Nordhausen RW, McCall MR. Apolipoprotein A-I-cell membrane interaction: extracellular assembly of heterogeneous nascent HDL particles. J Lipid Res. 1993 Feb;34(2):317-24.

Genest J. Lipoprotein disorders and cardiovascular risk. J Inherit Metab Dis. 2003;26(2-3):267-87. 
Ghosh J, Bose M, Roy S, Bhattacharyya SN. Leishmania donovani targets Dicer1 to downregulate miR-122, lower serum cholesterol, and facilitate murine liver infection. Cell Host Microbe. 2013 Mar;13(3):277-88.

Goldberg IJ. Lipoprotein lipase and lipolysis: central roles in lipoprotein metabolism and atherogenesis. J Lipid Res. 1996 Apr;37(4):693-707.

Goldenberg I, Benderly M, Goldbourt U. Update on the use of fibrates: focus on bezafibrate. Vasc Health Risk Manag. 2008;4(1):131-41.

Goto H, Lindoso JA. Immunity and immunosuppression in experimental visceral leishmaniasis. Braz J Med Biol Res. 2004 Apr;37(4):615-23.

Gotto AM Jr, Pownall HJ, Havel RJ. Introduction to the plasma lipoproteins. Methods Enzymol. 1986;128:3-41.

Goto H, Prianti Md. Immunoactivation and immunopathogeny during active visceral leishmaniasis. Rev Inst Med Trop Sao Paulo. 2009 Sep-Oct;51(5):241-6.

Grion CM, Cardoso LT, Perazolo TF, Garcia AS, Barbosa DS, Morimoto HK, Matsuo T, Carrilho AJ. Lipoproteins and CETP levels as risk factors for severe sepsis in hospitalized patients. Eur J Clin Invest. 2010 Apr;40(4):330-8.

Ha YC, Barter PJ. Differences in plasma cholesteryl ester transfer activity in sixteen vertebrate species. Comp Biochem Physiol B. 1982;71(2):265-9.

Hardardóttir I, Moser AH, Fuller J, Fielding C, Feingold K, Grünfeld C. Endotoxin and cytokines decrease serum levels and extra hepatic protein and mRNA levels of cholesteryl ester transfer protein in syrian hamsters. J Clin Invest. 1996 Jun;97(11):2585-92.

Hoeg JM, Brewer HB Jr. Human lipoprotein metabolism and the liver. Prog Liver Dis. 1986;8:51-64. 
Hommel M, Jaffe CL, Travi B, Milon G. Experimental models for leishmaniasis and for testing anti-leishmanial vaccines. Ann Trop Med Parasitol. 1995 Dec;89 Suppl 1:55-73.

Jeong S, Kim M, Han M, Lee H, Ahn J, Kim M, et al. Fenofibrate prevents obesity and hypertriglyceridemia in low-density lipoprotein receptor-null mice. Metabolism. 2004 May;53(5):607-13.

Jiang XC, Moulin P, Quinet E, Goldberg IJ, Yacoub LK, Agellon LB, et al. Mammalian adipose tissue and muscle are major sources of lipid transfer protein mRNA. J Biol Chem. 1991 Mar;266(7):4631-9.

Kawakami M, Cerami A. Studies of endotoxin-induced decrease in lipoprotein lipase activity. J Exp Med. 1981 Sep;154(3):631-9.

Kersten S, Desvergne B, Wahli W. Roles of PPARs in health and disease. Nature. 2000 May;405:421-24.

Kim JB, Spiegelman BM. ADD1/SREBP1 promotes adipocyte differentiation and gene expression linked to fatty acid metabolism. Genes Dev. 1996 May;10(9): 1096107.

Khovidhunkit W, Memon RA, Feingold KR, Grunfeld C. Infection and inflammation-induced proatherogenic changes of lipoproteins. J Infect Dis. 2000 Jun;181 Suppl 3:S462-72.

Lal CS, Kumar A, Kumar S, Pandey K, Kumar N, Bimal S, et al. Hypocholesterolemia and increased triglyceride in pediatric visceral leishmaniasis. Clin Chim Acta. 2007 Jul;382(1-2):151-3.

Lal CS, Verma N, Rabidas VN, Ranjan A, Pandey K, Verma RB, et al. Total serum cholesterol determination can provide understanding of parasite burden in patients with visceral leishmaniasis infection. Clin Chim Acta. 2010 Dec;411(23-24):2112-3.

Liberopoulos E, Alexandridis G, Bairaktari E, Elisaf M. Severe hypocholesterolemia with reduced serum lipoprotein (a) in a patient with visceral leishmaniasis. Ann Clin Lab Sci. 2002;32(3):305-8. 
Luo Y, Tall AR. Sterol upregulation of human CETP expression in vitro and in transgenic mice by an LXR element. J Clin Invest. 2000 Feb;105(4):513-20.

Maillard P, Walic M, Meuleman P, Roohvand F, Huby T, Le Goff W, et al. Lipoprotein lipase inhibits hepatitis $\mathrm{C}$ virus (HCV) infection by blocking virus cell entry. PLoS One. 2011;6(10):e26637.

Martinez LRC, Santos RD. Papel dos fibratos no tratamento das dislipidemias. São Paulo: BBS Editora; 2004. Manual de dislipidemias e cardiometabolismo; p. 157165.

Masucci-Magoulas L, Plump A, Jiang XC, Walsh A, Breslow JL, Tall AR. Profound induction of hepatic cholesteryl ester transfer protein transgene expression in apolipoprotein $\mathrm{E}$ and low density lipoprotein receptor gene knockout mice. A novel mechanism signals changes in plasma cholesterol levels. J Clin Invest. 1996 Jan;97(1):154-61.

Melby PC, Chandrasekar B, Zhao W, Coe JE. The hamster as a model of human visceral leishmaniasis: progressive disease and impaired generation of nitric oxide in the face of a prominent Th1-like cytokine response. J Immunol. 2001 Feb;166(3):191220 .

Myler PJ, Fasel, N. Leishmaniasis: epidemiological trends and diagnosis. Norfolk: Caister Academic Press; 2008. Leishmania after the genome; p. 1-14.

Murray HW, Stern JJ, Welte K, Rubin BY, Carriero SM, Nathan CF. Experimental visceral leishmaniasis: production of interleukin 2 and interferon-gamma, tissue immune reaction, and response to treatment with interleukin 2 and interferongamma. J Immunol. 1987 Apr;138(7):rbos2290-7.

Nieto CG, Barrera R, Habela MA, Navarrete I, Molina C, Jiménez A, et al. Changes in the plasma concentrations of lipids and lipoprotein fractions in dogs infected with Leishmania infantum. Vet Parasitol. 1992 Oct;44(3-4):175-82.

Nistor A, Bulla A, Filip DA, Radu A. The hyperlipidemic hamster as a model of experimental atherosclerosis. Atherosclerosis. 1987 Nov;68(1-2):159-73.

Okumura-Noji K, Miura Y, Lu R, Asai K, Ohta N, Brindley PJ, Yokoyama S. CD36related protein in Schistosoma japonicum: candidate mediator of selective cholesteryl 
ester uptake from high-density lipoprotein for egg maturation. FASEB J. 2013 Mar;27(3):1236-44.

Ottoni CI. A infecção por Leishmania infantum chagasi altera o metabolism lipídico do hospedeiro. [Dissertação]. Natal: Universidade Federal do Rio Grande do Norte; 2010. 86p.

Pfaffl MW, Lange IG, Daxenberger A, Meyer HH. Tissue-specific expression pattern of estrogen receptors (ER): quantification of ER alpha and ER beta mRNA with realtime RT-PCR. Acta Path Microbiol et Immunol Scandinavic. 2001 May;109(5):34555.

Pinelli E, Gonzalo RM, Boog CJ, Rutten VP, Gebhard D, del Real G, et al. Leishmania infantum-specific $\mathrm{T}$ cell lines derived from asymptomatic dogs that lyse infected macrophages in a major histocompatibility complex-restricted manner. Eur J Immunol. 1995 Jun;25(6):1594-600.

Pirela VB, Souki A, Ponce CC, Arias FB, Moreno EM, Gonzalez EL, et al. Ciprofibrate diminishes non-HDLC and improves HDLC in patients with Frederickson type IV dyslipidemia phenotype. Archivos Venezelanos de Farmacología y Terapéutica. 2005;24(2).

Pucadyil TJ, Tewary P, Madhubala R, Chattopadhyay A. Cholesterol is required for Leishmania donovani infection: implications in leishmaniasis. Mol Biochem Parasitol. 2004 Feb;133(2):145-52.

Quinet EM, Agellon LB, Kroon PA, Marcel YL, Lee YC, Whitlock ME, Tall AR. Atherogenic diet increases cholesteryl ester transfer protein messenger RNA levels in rabbit liver. J Clin Invest. 1990 Feb;85(2):357-63.

Quintão EC, Cazita PM. Lipid transfer proteins: past, present and perspectives. Atherosclerosis. 2010 Mar;209(1):1-9.

Rosenzweig D, Smith D, Opperdoes F, Stern S, Olafson RW, Zilberstein D. Retooling Leishmania metabolism: from sand fly gut to human macrophage. FASEB J. 2008 Feb;22(2):590-602.

Rossi MA, Celes MR, Prado CM, Saggioro FP. Myocardial structural changes in long-term human severe sepsis/septic shock may be responsible for cardiac dysfunction. Shock. 2007 Jan;27(1):10-8. 
Sammalkorpi K, Valtonen V, Kerttula Y, Nikkilä E, Taskinen MR. Changes in serum lipoprotein pattern induced by acute infections. Metabolism. 1988 Sep;37(9):859-65.

Schoonjans K, Peinado-Onsurbe J, Lefebvre AM, Heyman RA, Briggs M, Deeb S, et al. PPARalpha and PPARgamma activators direct a distinct tissue-specific transcriptional response via a PPRE in the lipoprotein lipase gene. EMBO J. 1996 Oct;15(19):5336-48.

Seçmeer G, Cengiz AB, Gurgey A, Kara A, Cultu O, Tavil B. Hypertriglyceridemia and decreased high-density lipoprotein could be a clue for visceral leishmaniasis. Infect Dis Clin Pract 2006;14:401-402.

Semenkovich CF, Chen SH, Wims M, Luo CC, Li WH, Chan L. Lipoprotein lipase and hepatic lipase mRNA tissue specific expression, developmental regulation, and evolution. J Lipid Res. 1989 Mar;30(3):423-31.

Soares NM, Leal TF, Fiúza MC, Reis EA, Souza MA, Dos-Santos WL, et al. Plasma lipoproteins in visceral leishmaniasis and their effect on Leishmania-infected macrophages. Parasite Immunol. 2010 Apr;32(4):259-66.

Sparks CE, Hnatiuk O, Marsh JB. Hepatic and intestinal contribution of two forms of apolipoprotein B to plasma lipoprotein fractions in the rat. Can J Biochem. 1981 Aug;59(8):693-9.

Srivastava, R.A, Jahagirdar, R, Azhar S., Sharma, S., Bisgaier, C.L. Peroxisome proliferator-activated receptor-alpha selective ligand reduces adiposity, improves insulin sensitivity and inhibits atherosclerosis in LDL receptor-deficient mice. Mol Cell Biochem. 2006;285:35-50.

Staels B, van Tol A, Andreu T, Auwerx J. Fibrates influence the expression of genes involved in lipoprotein metabolism in a tissue-selective manner in the rat. Arterioscler Thromb. 1992 Mar;12(3):286-94.

Staels B, Dallongeville J, Auwerx J, Schoonjans K, Leitersdorf E, Fruchart JC. Mechanism of action of fibrates on lipid and lipoprotein metabolism. Circulation. 1998 Nov 10;98(19):2088-93. 
Stauber LA. Host resistance to the Kharthoum strain of Leishmania donovani. Rice Inst Pamphlet. 1958;45:80-96.

Sullivan MP, Cerda JJ, Robbins FL, Burgin CW, Beatty RJ. The gerbil, hamster, and guinea pig as rodent models for hyperlipidemia. Lab Anim Sci. 1993 Dec;43(6):5758.

Tall AR. Plasma cholesteryl ester transfer protein and high-density lipoproteins: new insights from molecular genetic studies. J Intern Med. 1995 Jan;237(1):5-12.

Tall AR, Sammett D, Vita GM, Deckelbaum R, Olivecrona T. Lipoprotein lipase enhances the cholesteryl ester transfer protein-mediated transfer of cholesteryl esters from high density lipoproteins to very low density lipoproteins. J Biol Chem. 1984 Aug;259(15):9587-94.

Vasconcellos RC, Urago KP, Bunn-Moreno MM, Madeira ED. Suppressor activity in Leishmania donovani-infected hamster serum: reversion by delipidated bovine serum albumin and role in cell cycle events. Braz J Med Biol Res. 1996 May;29(5):615-22.

Viswakarma N, Jia Y, Bai L, Vluggens A, Borensztajn J, Xu J, Reddy JK. Coactivators in PPAR-Regulated Gene Expression. PPAR Res. 2010;doi:pii:250126. $10.1155 / 2010 / 250126$.

WHO. Control of the leishmaniasis: report of a meeting of the WHO Expert Committee on the Control of Leishmaniasis. Techicnal Report Series 949.Geneva. 2010.

Xie C, Wang ZC, Liu XF, Yang MS. The common biological basis for common complex diseases: evidence from lipoprotein lipase gene. Eur J Hum Genet. 2010 Jan;18(1):3-7.

Yacoub LK, Vanni TM, Goldberg IJ. Lipoprotein lipase mRNA in neonatal and adult mouse tissues: comparison of normal and combined lipase deficiency (cld) mice assessed by in situ hybridization. J Lipid Res. 1990 Oct;31(10):1845-52.

Yao Z, McLeod RS. Synthesis and secretion of hepatic apolipoprotein B-containing lipoproteins. Biochim Biophys Acta. 1994 May;1212(2):152-66. 


\section{ANEXO A - Comitê de Ética do IMTSP/USP}

UNIVERSIDADE DE SÃO PAULO
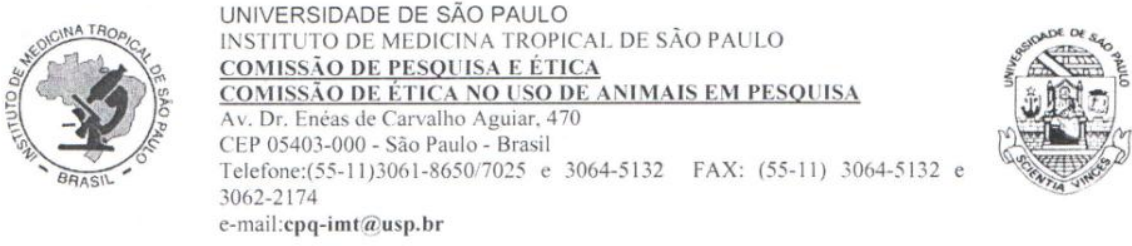

e-mail:cpq-imt@usp.br

São Paulo, 28 de setembro de 2011.

IImo (a)

Dra. HIRO GOTO

(aos cuidados de Ive Maíra de Carvalho Dantas)

Em reunião na presente data, a Comissão de Pesquisa e Ética e Comissão de Ética no Uso de Animais em Pesquisa, do Instituto de Medicina Tropical de São Paulo, analisou e aprovou, no que diz respeito aos aspectos de natureza da ética em experimentação animal, o projeto de pesquisa classificado sob número CPE-IMT 2011/107 e intitulado "Alteração do perfil lipídico na Leishmaniose visceral em hamster: correlação da expressão de mRNA de PPAR alfa e lipoproteina lipase e efeito do ciprofibrato", sob a sua responsabilidade.

Atenciosamente,

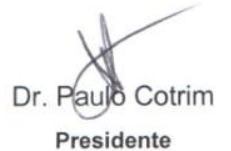

Comissão de Pesquisa e Ética do IMT-USP

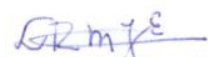

Dra. Luciana Regina Meireles Jaguaribe Ekman

Coordenadora da Comissão de Ética no Uso de Animais em Pesquisa do IMT-USP 